\title{
Supplemental Information for The Catalytic Asymmetric Synthesis of Morpholines. Using Mechanistic Insights to Realize the Enantioselective Synthesis of Piperazines
}

Ying Yin Lau, Huimin Zhai, and Laurel L. Schafer*

Department of Chemistry, University of British Columbia, 2036 Main Mall, Vancouver, BC V6T 1 Z1 Canada 


\section{Table of Contents}

$\begin{array}{ll}\text { NMR Spectra for New Compounds } & \text { Page } 2\end{array}$

$\begin{array}{ll}\text { Chromatograms for } e e \text { Determination } & \text { Page } 36\end{array}$ 

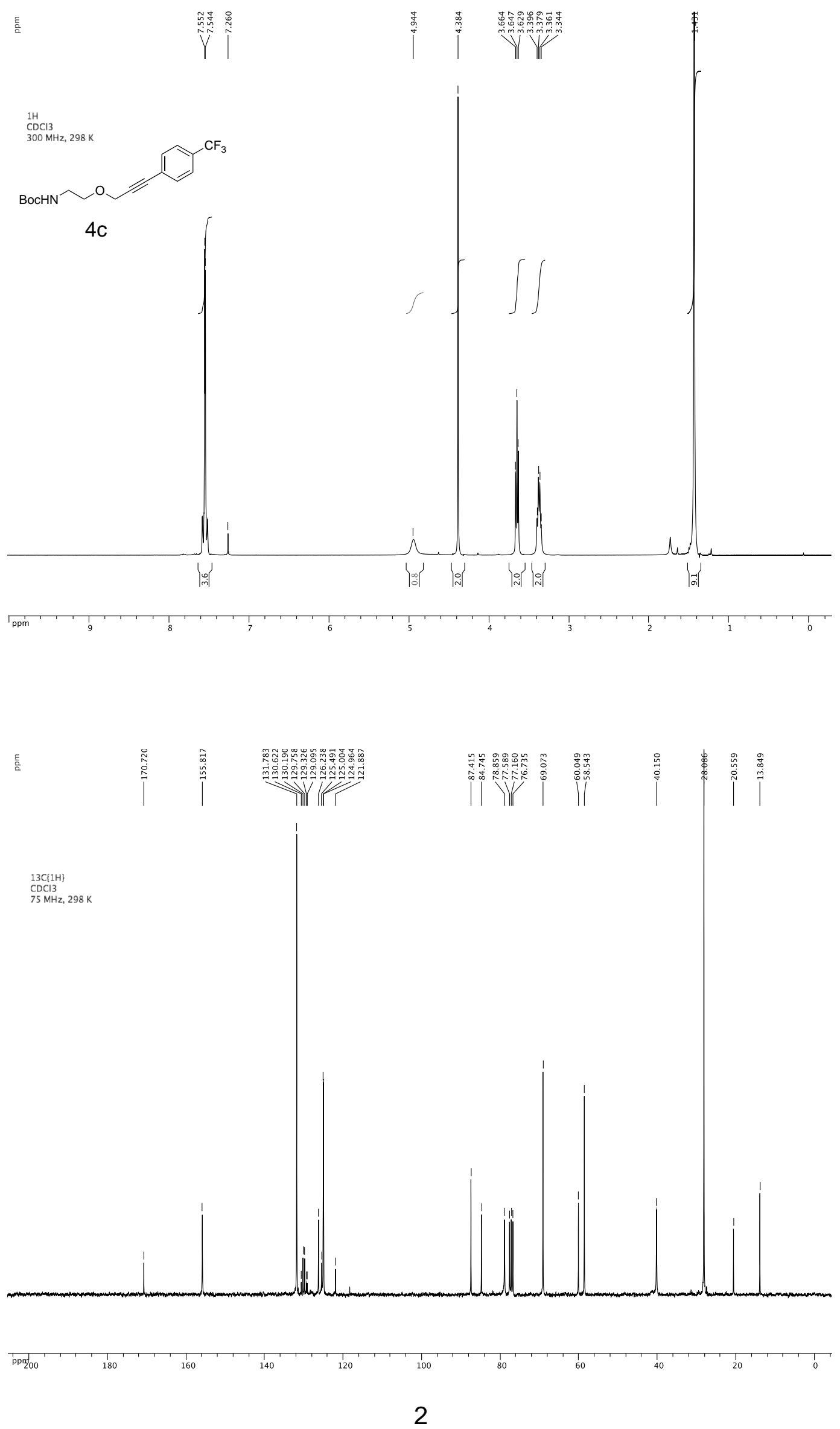


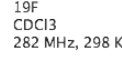

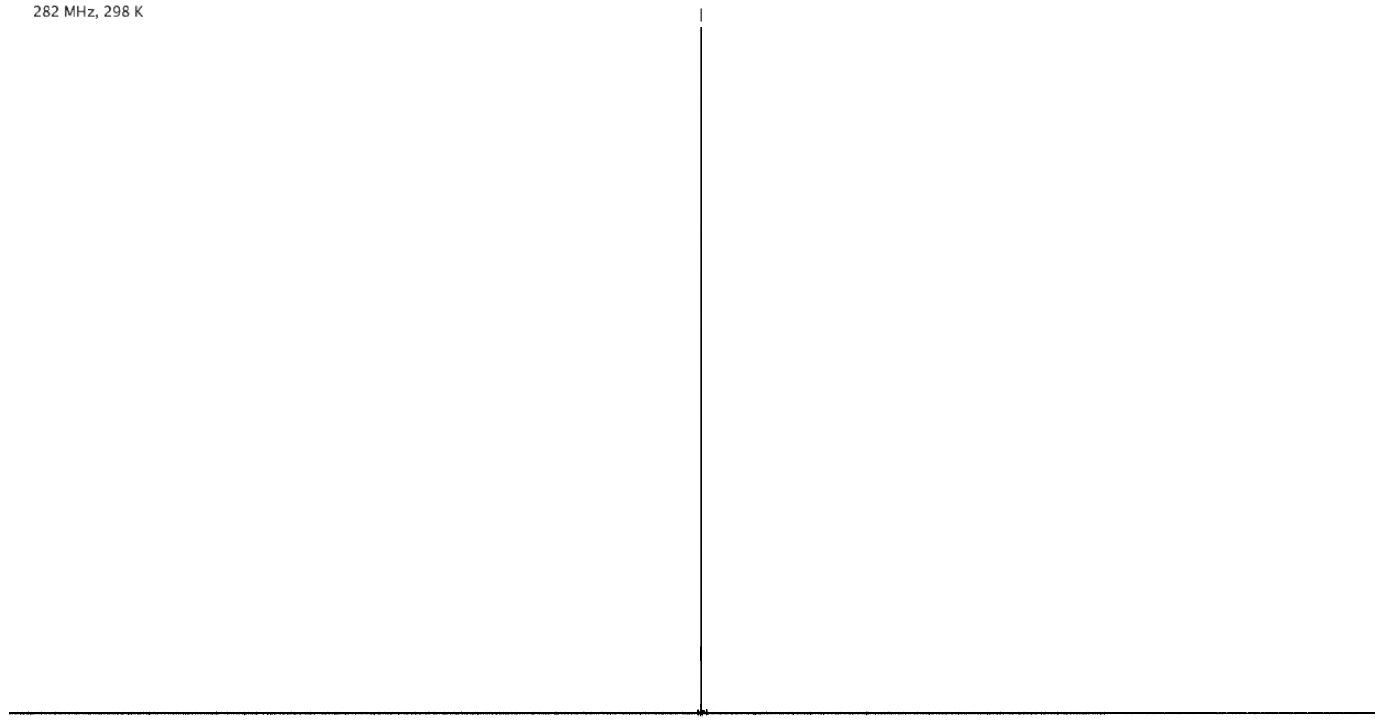

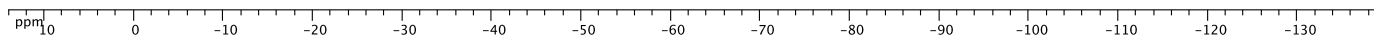



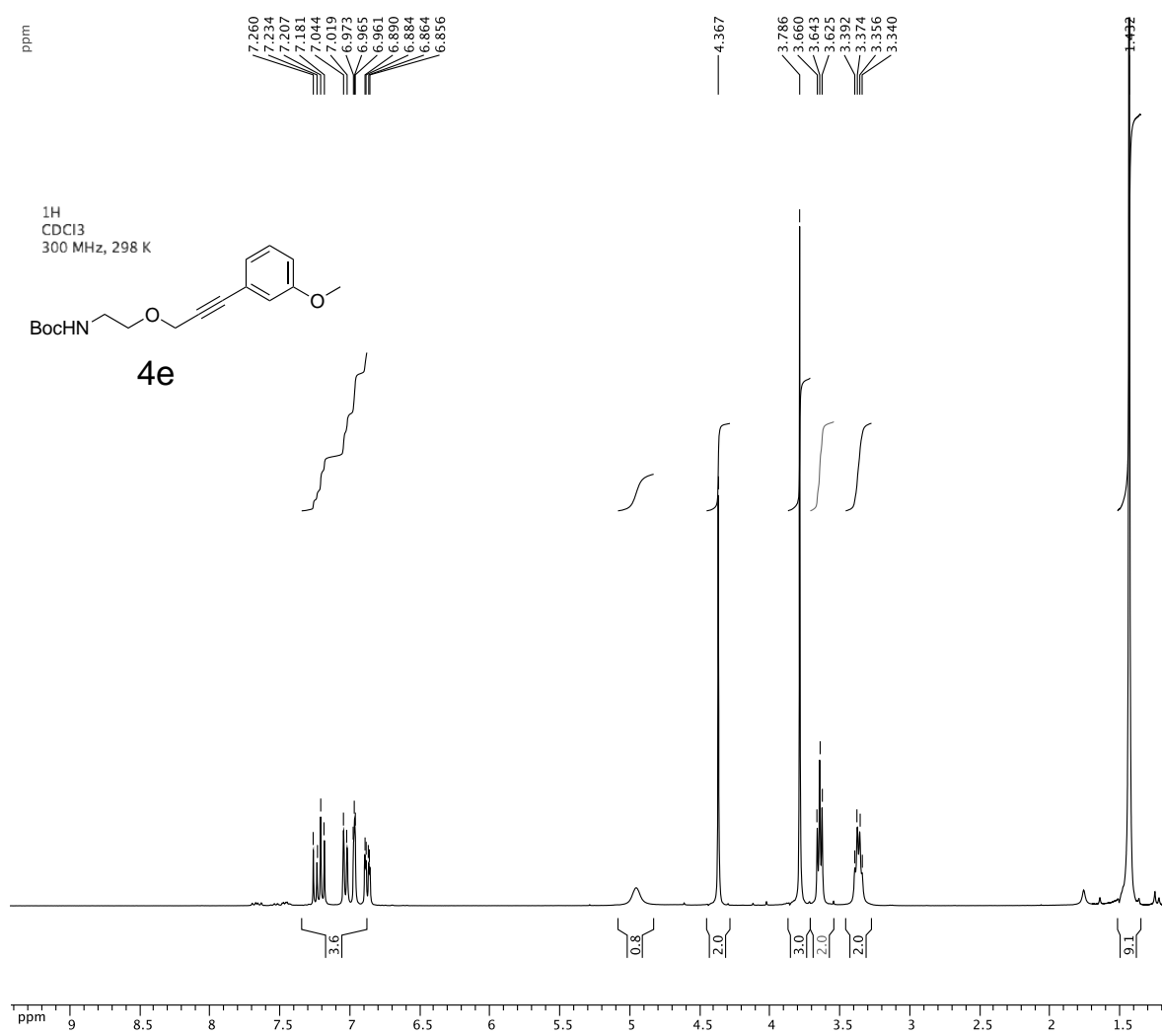

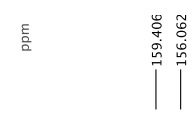

$\mid$

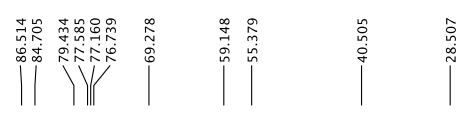

$13 \mathrm{C}\{1 \mathrm{H}\}$

$75 \mathrm{MHz}, 298 \mathrm{~K}$
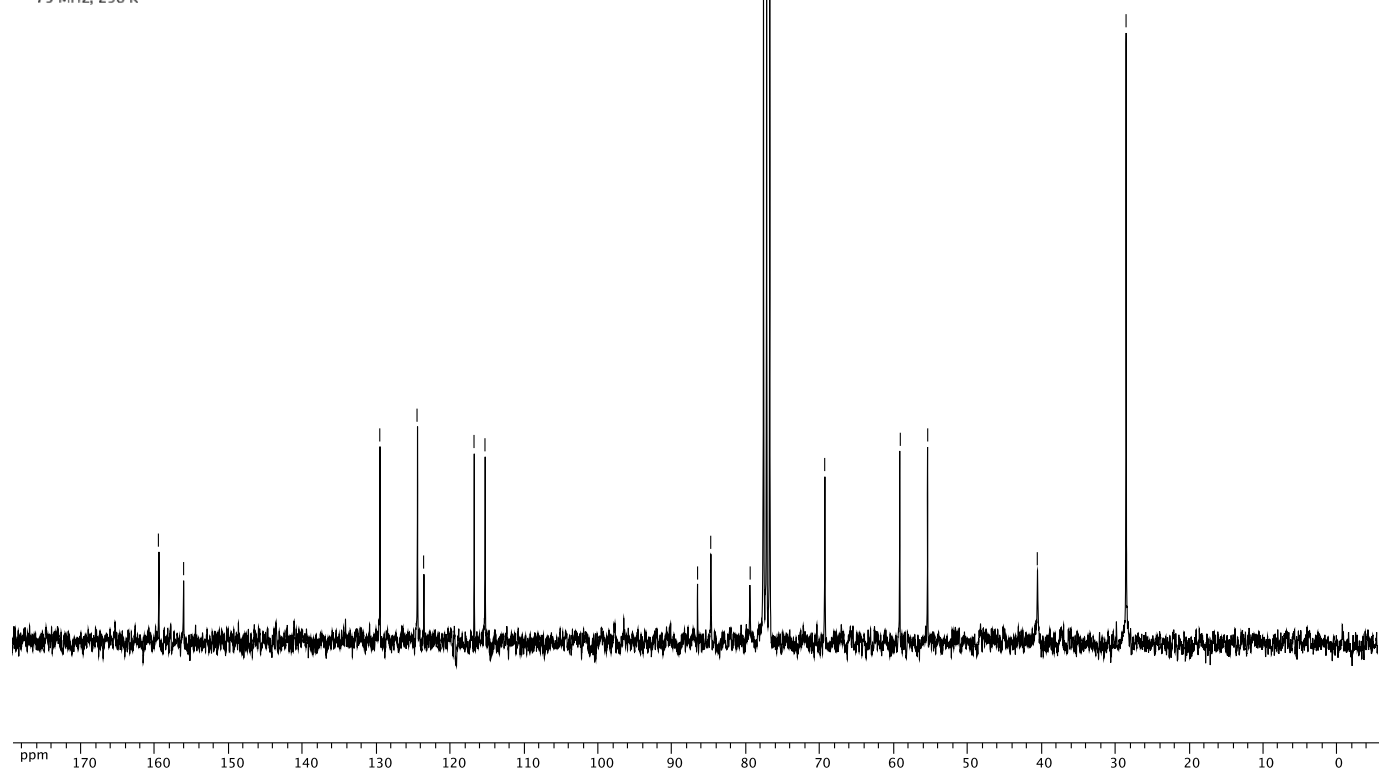

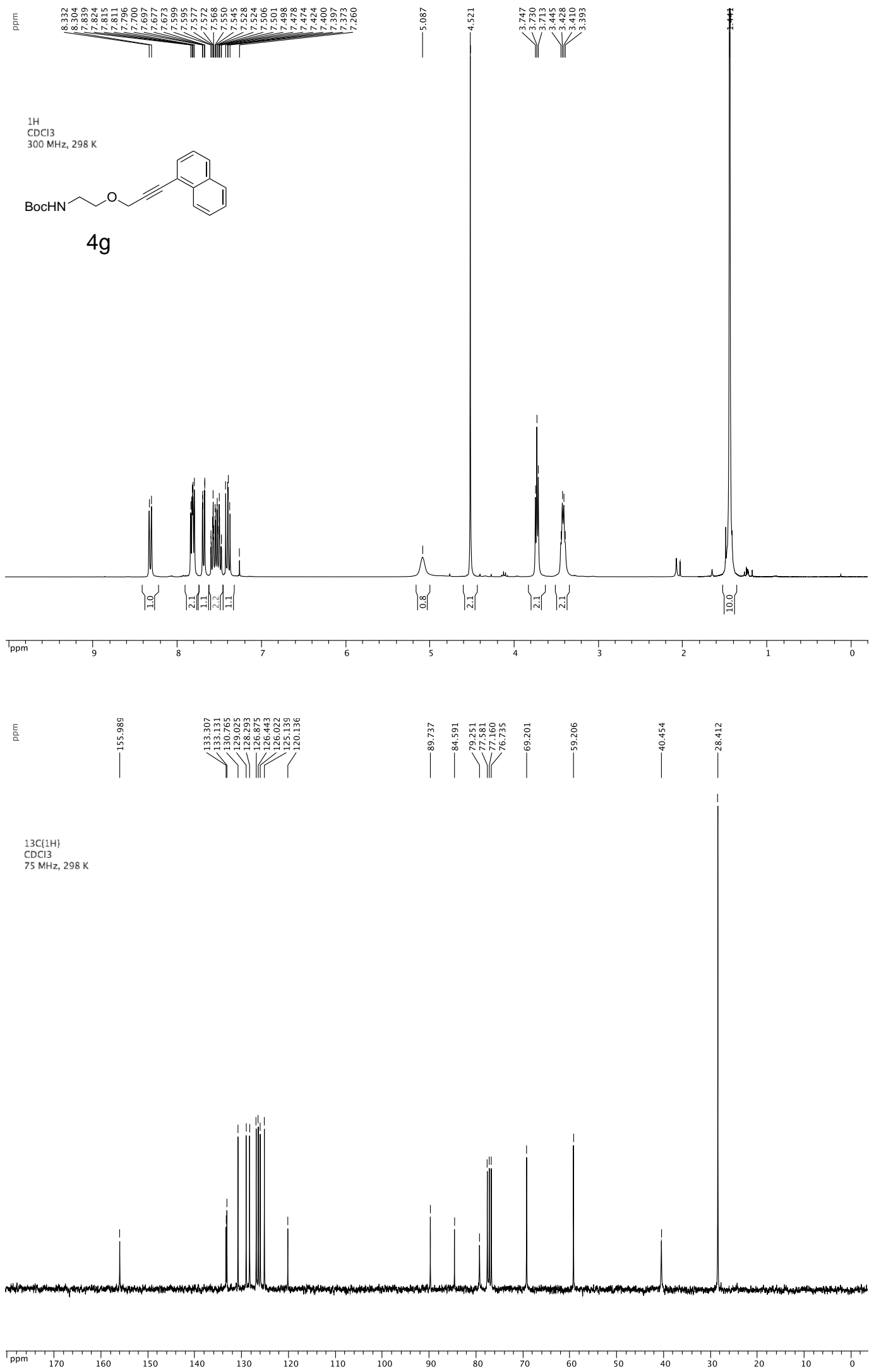

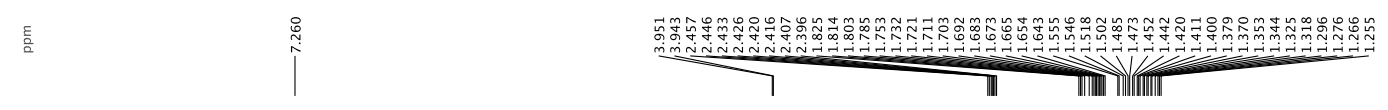

$1 \mathrm{H}$
$\mathrm{CDCl} 3$
$300 \mathrm{MHz}, 298 \mathrm{~K}$
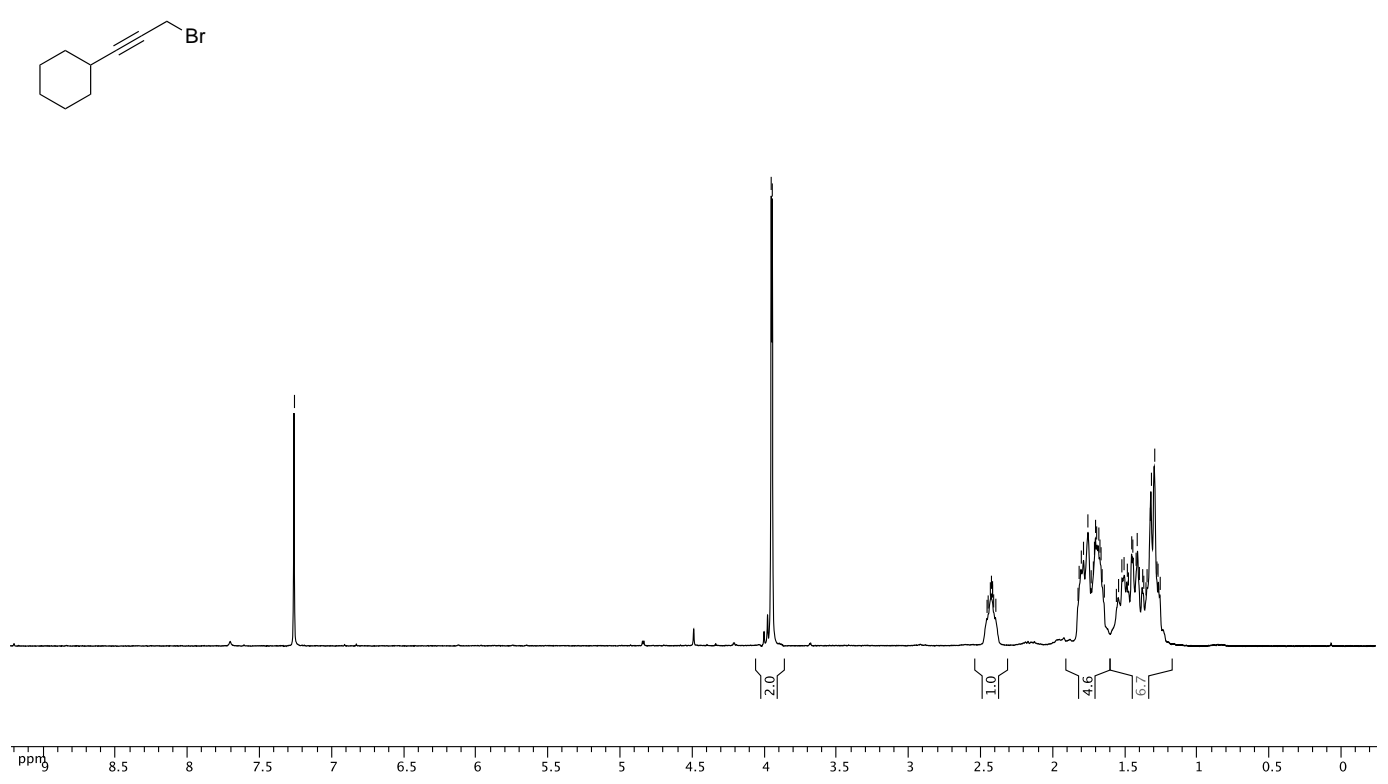

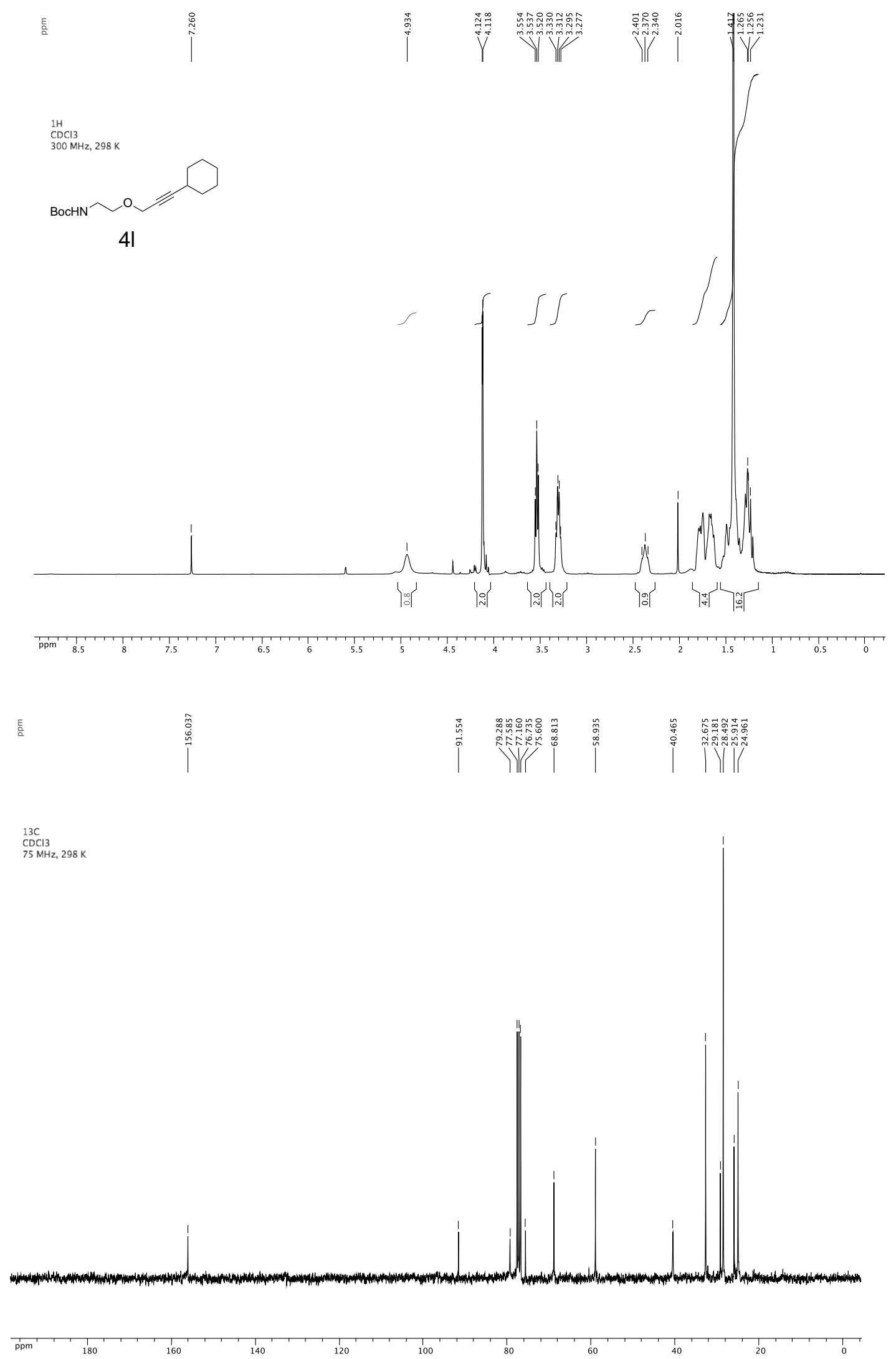

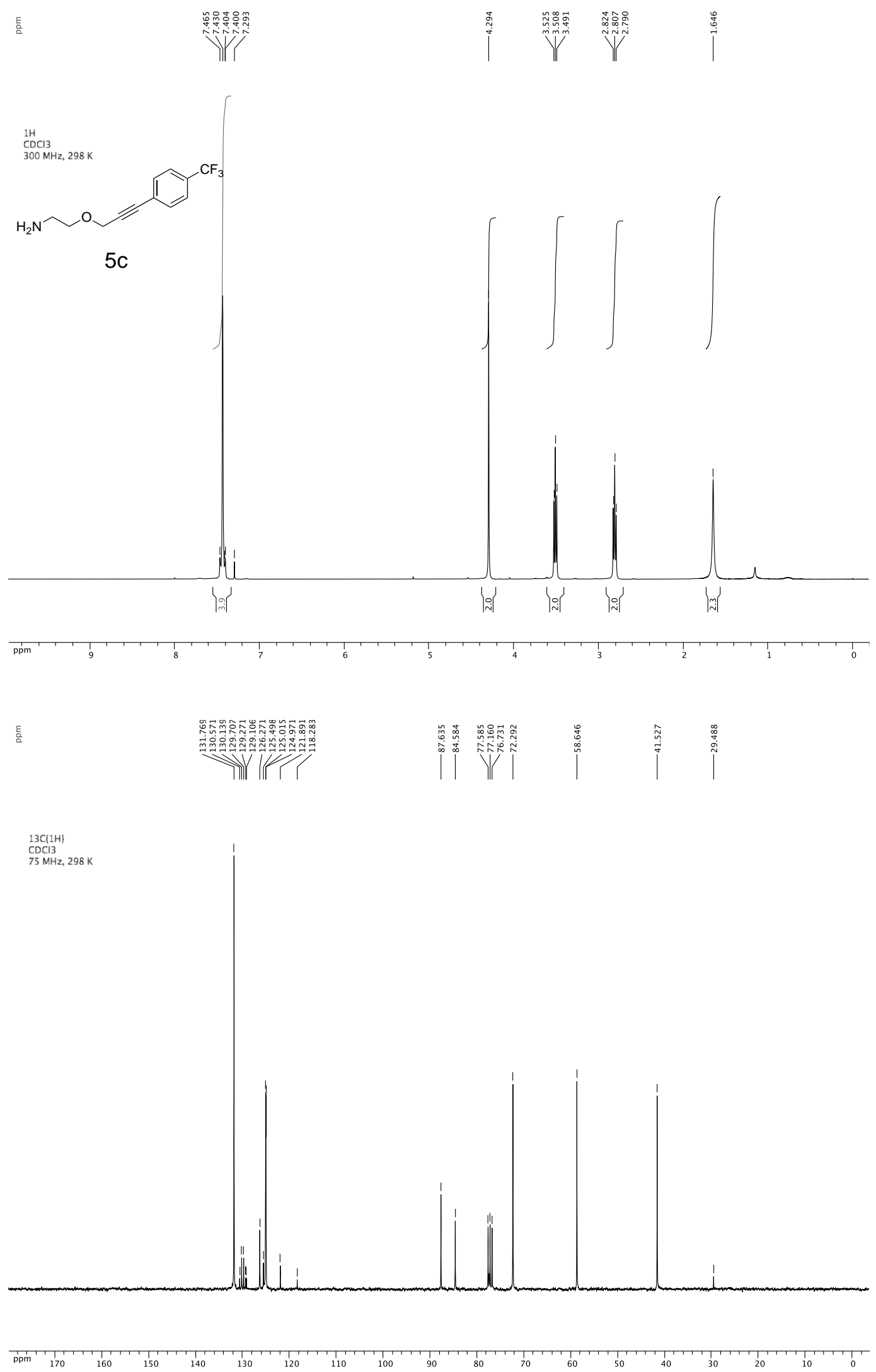
${ }_{10 \mathrm{~F}}^{10}$
${ }_{282} \mathrm{NHZ}, 298 \mathrm{~K}$

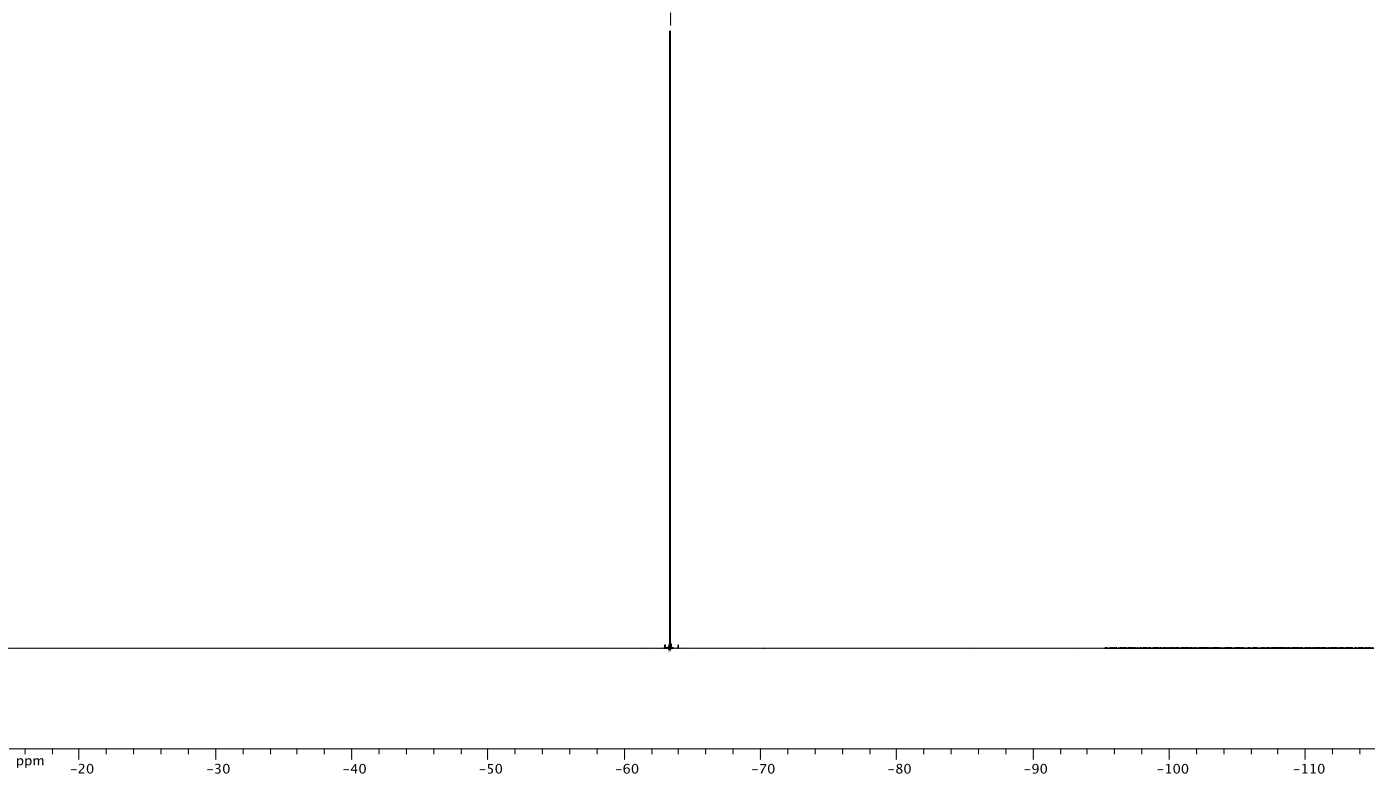



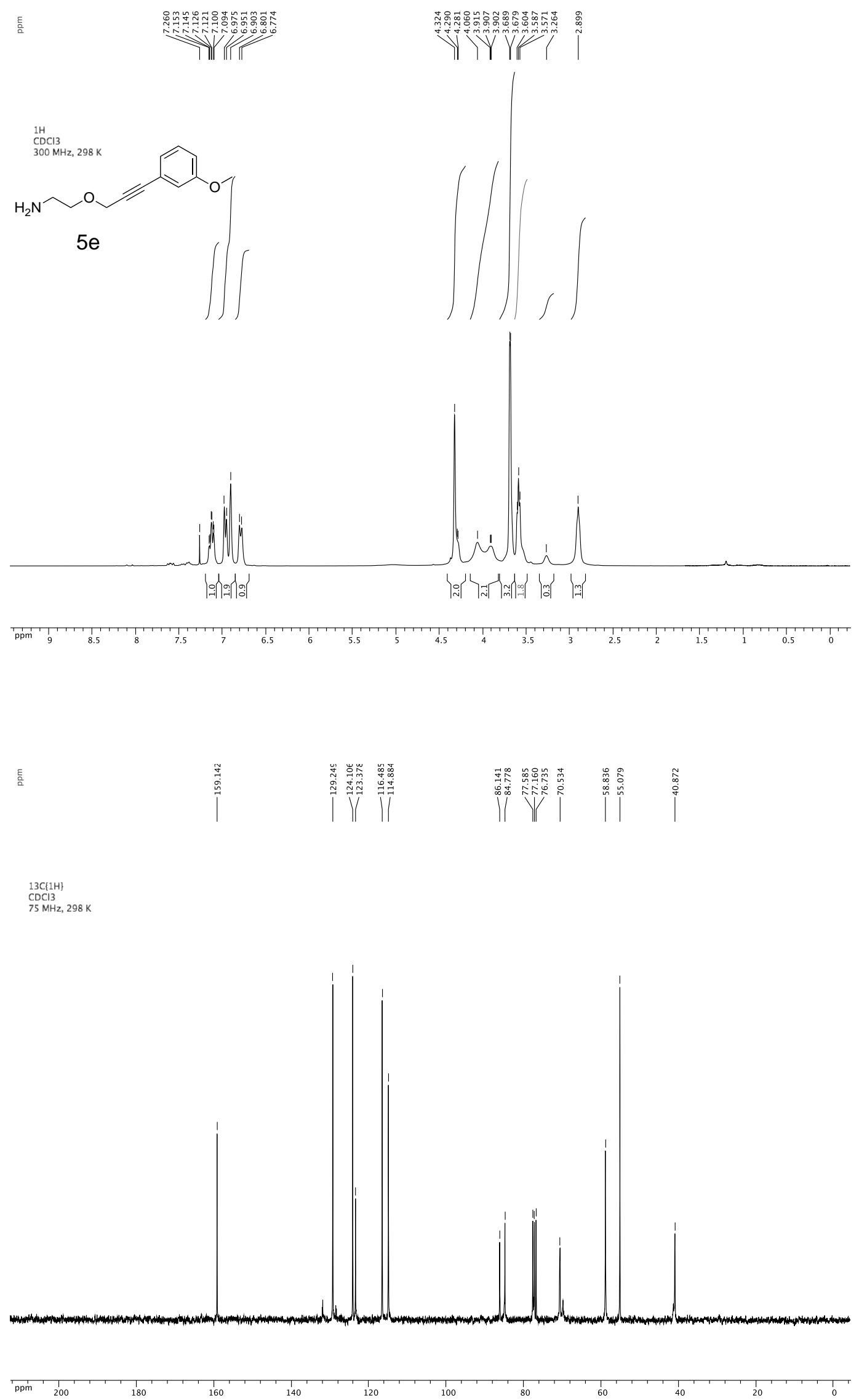

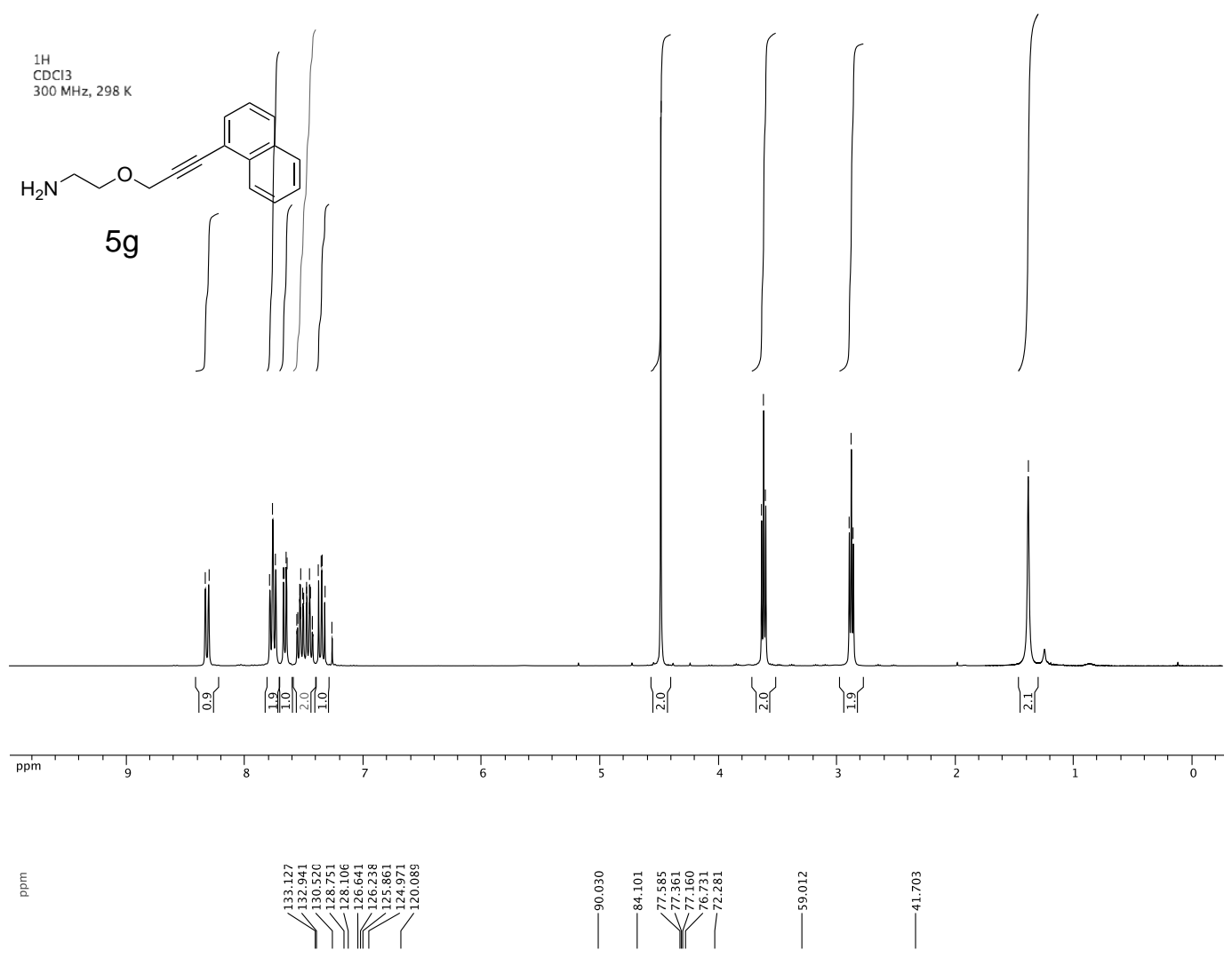

$13 \mathrm{C}\{1 \mathrm{H}\}$

$75 \mathrm{MHz}, 298 \mathrm{~K}$
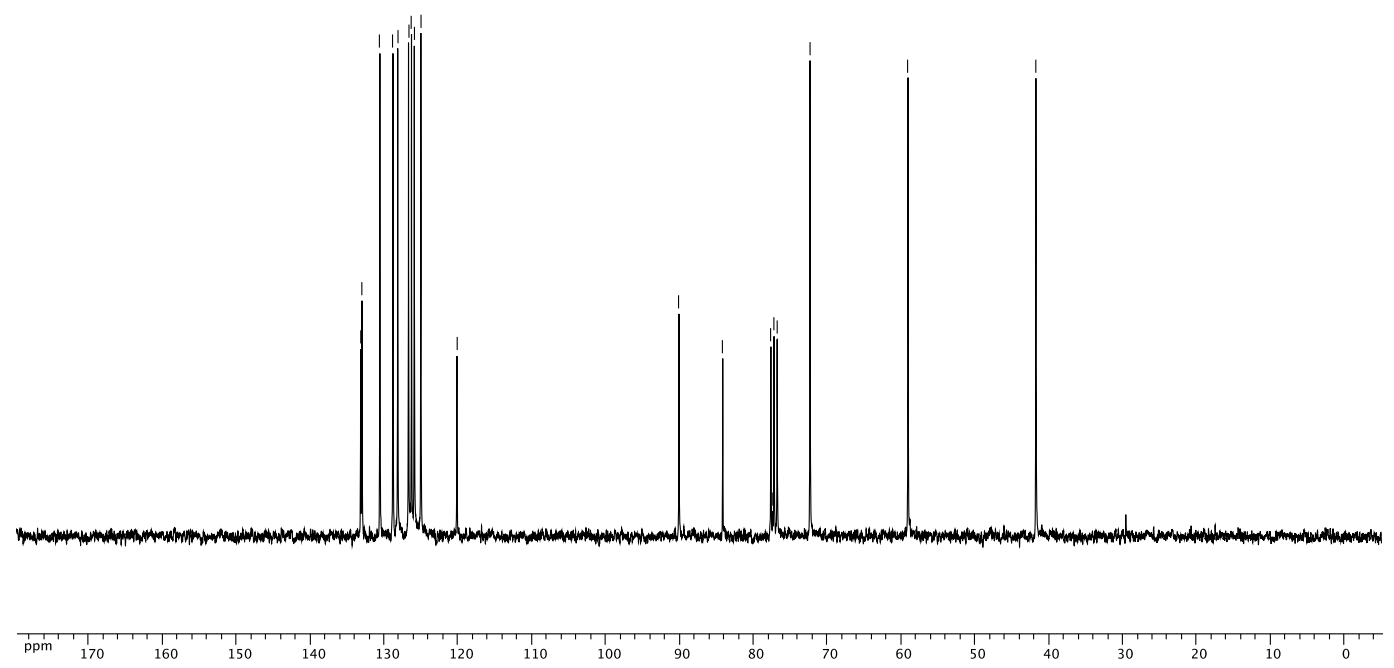

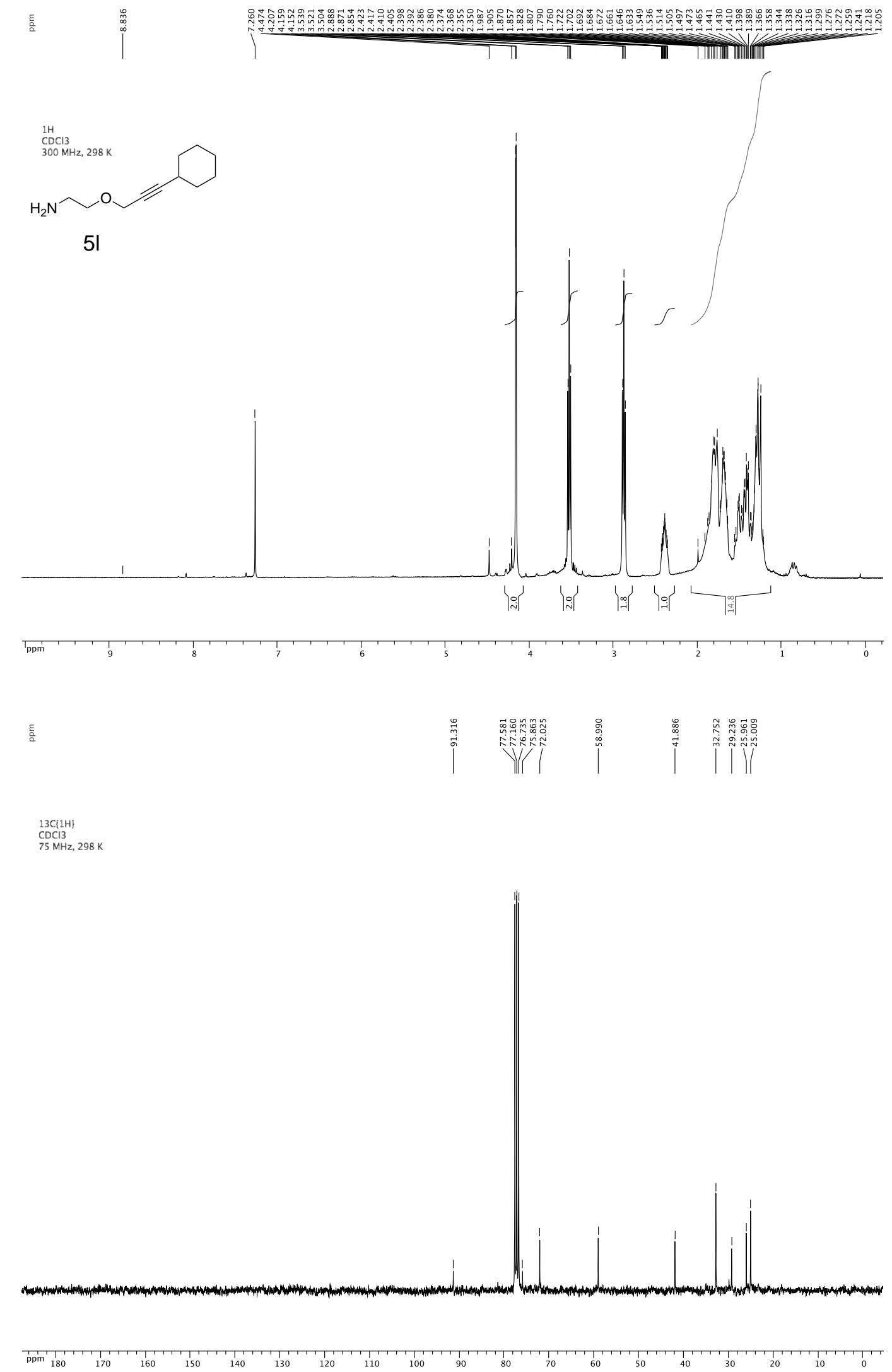


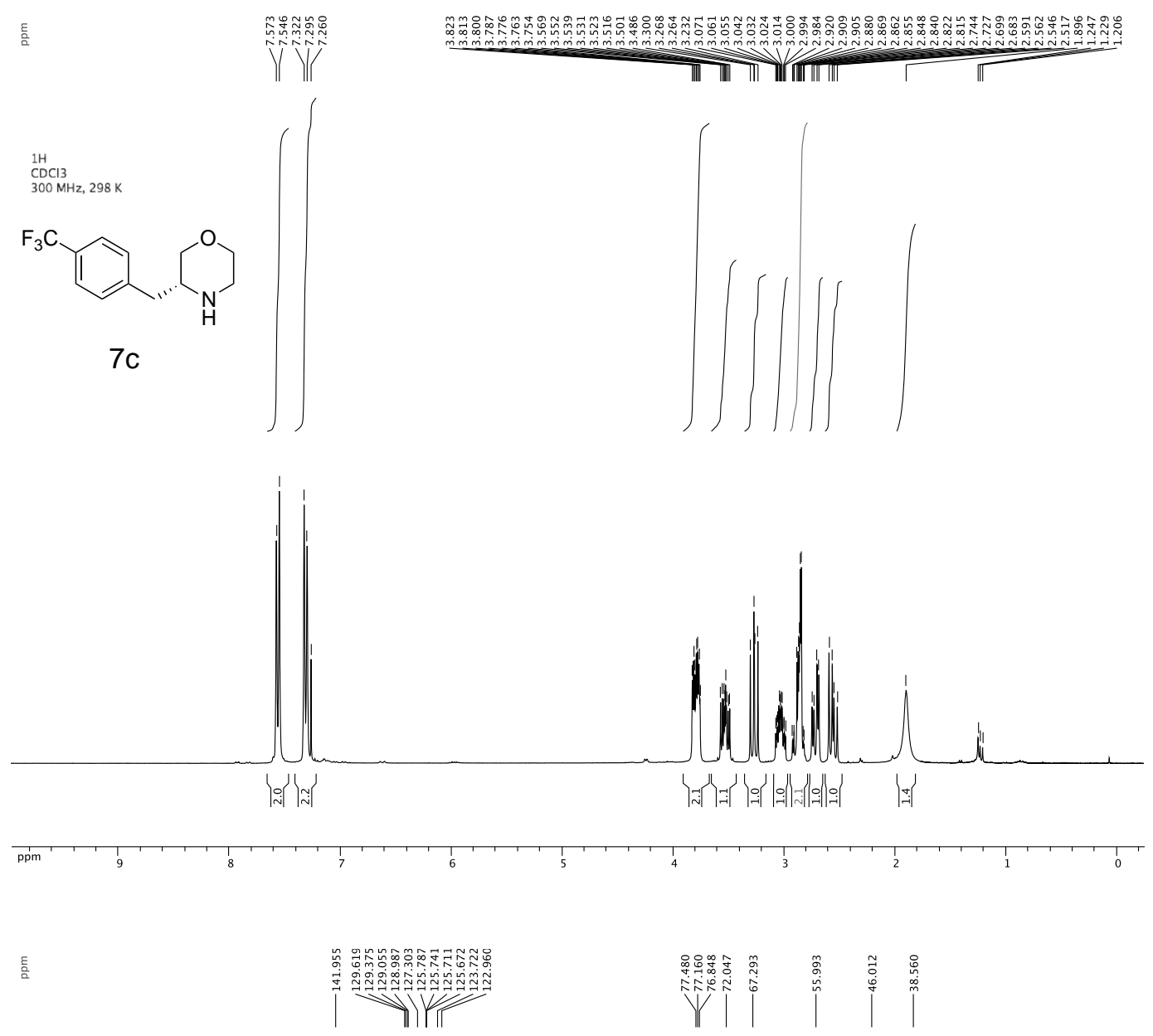

$13 \mathrm{C}\{1 \mathrm{H}\}$

$100 \mathrm{MHz}, 298 \mathrm{~K}$

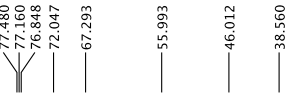
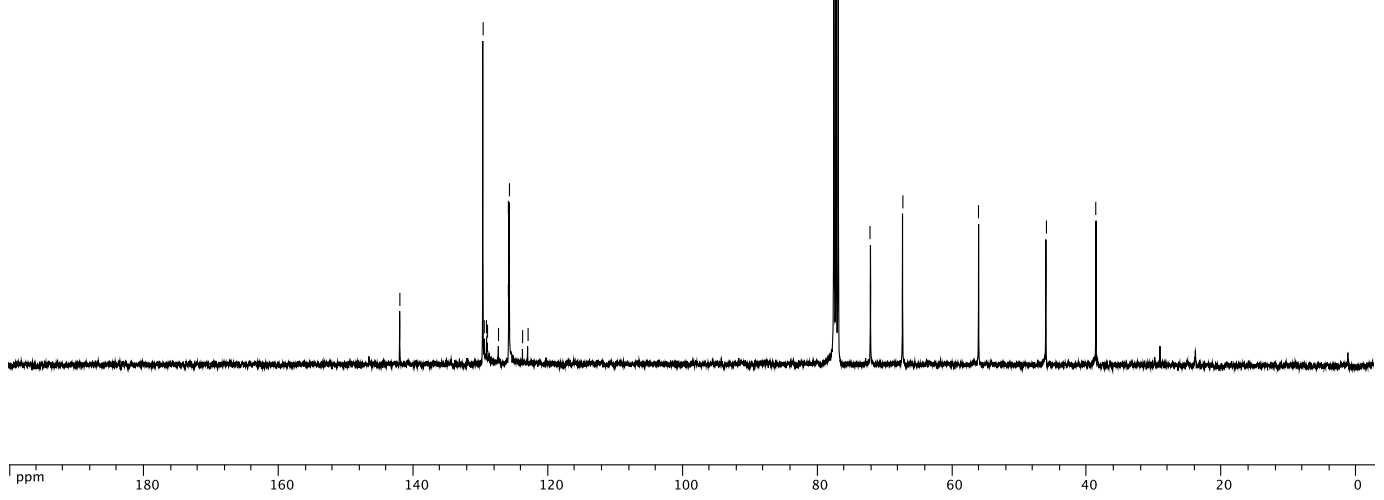
19F
CDCl3
$282 \mathrm{MHz}, 298 \mathrm{~K}$

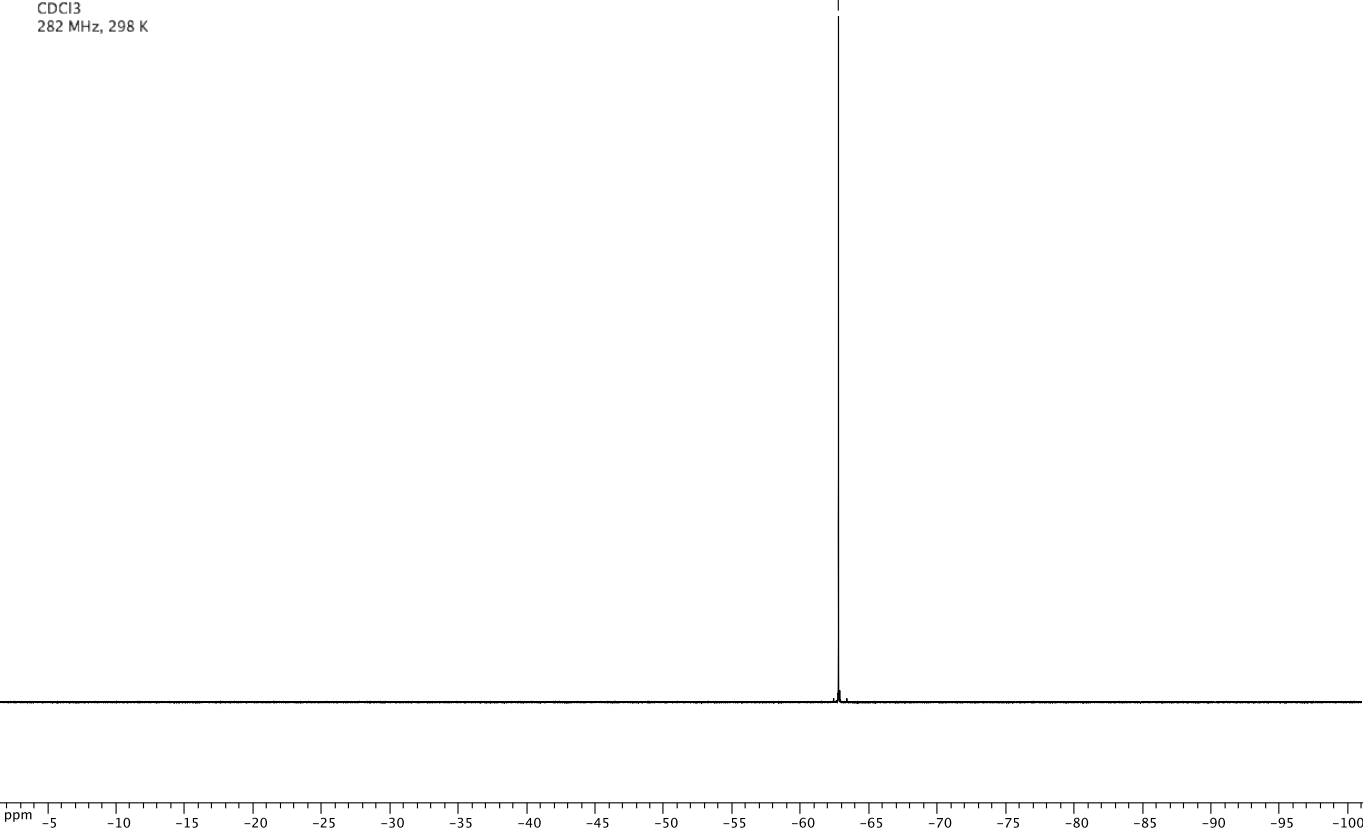



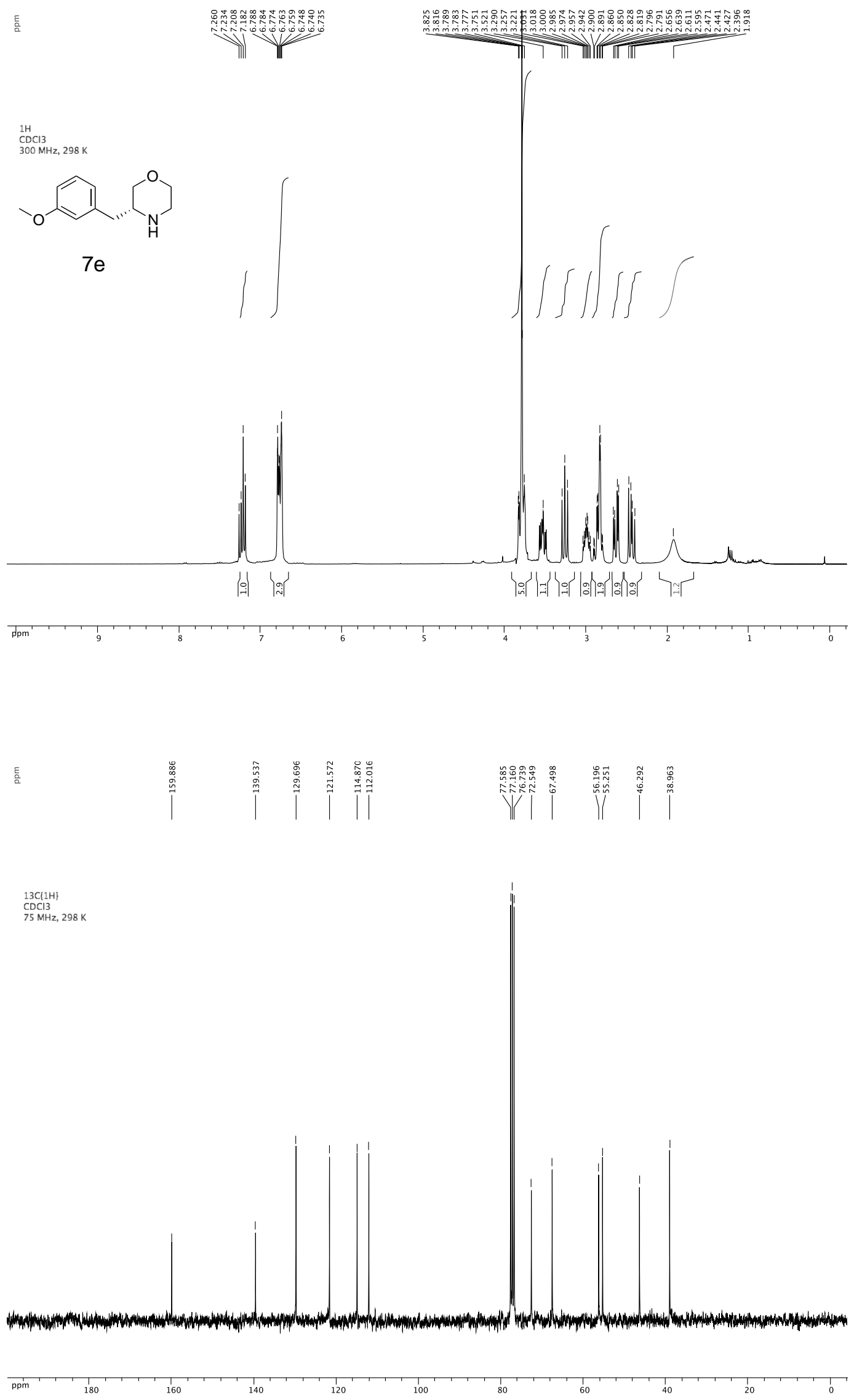

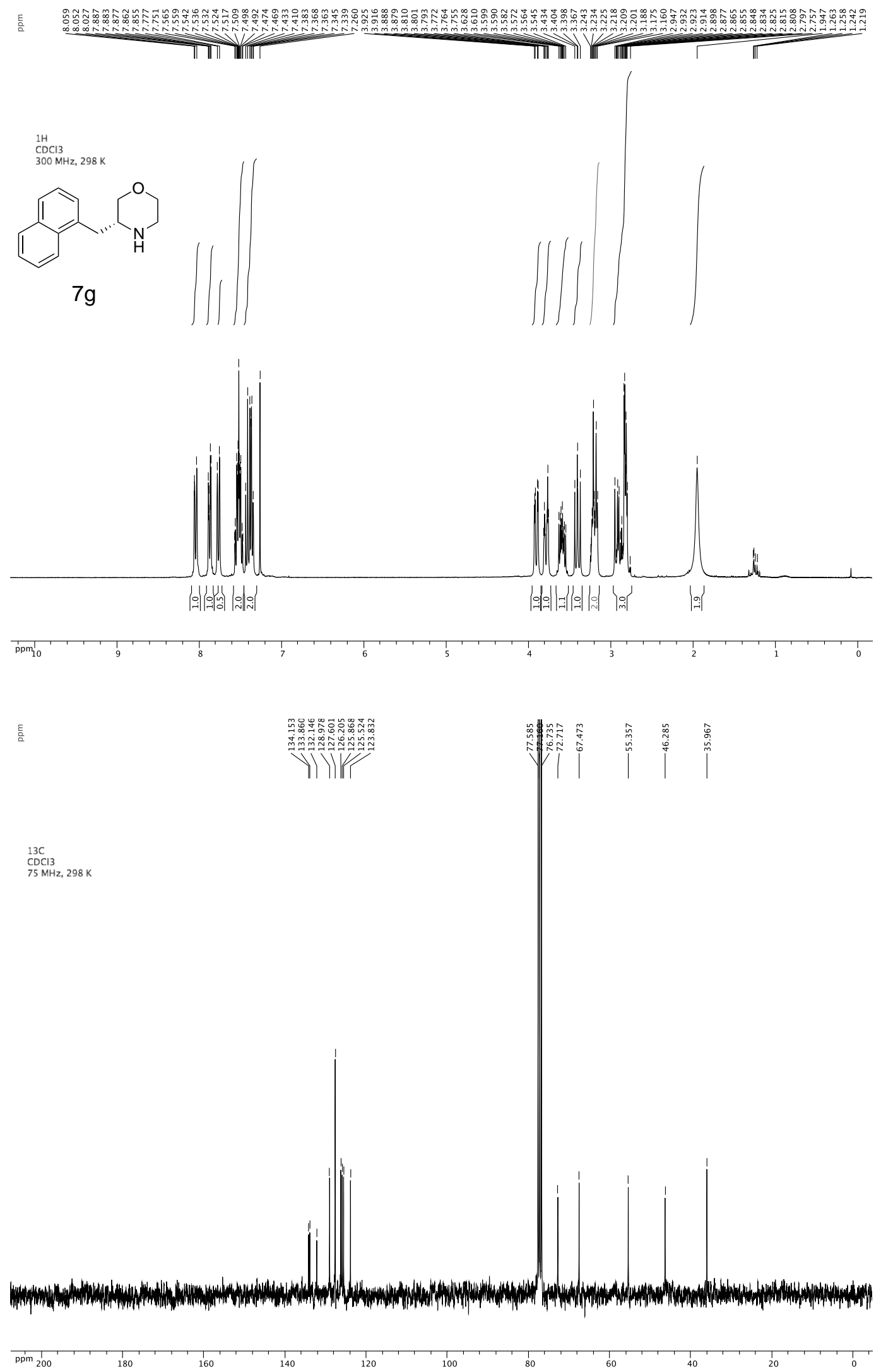

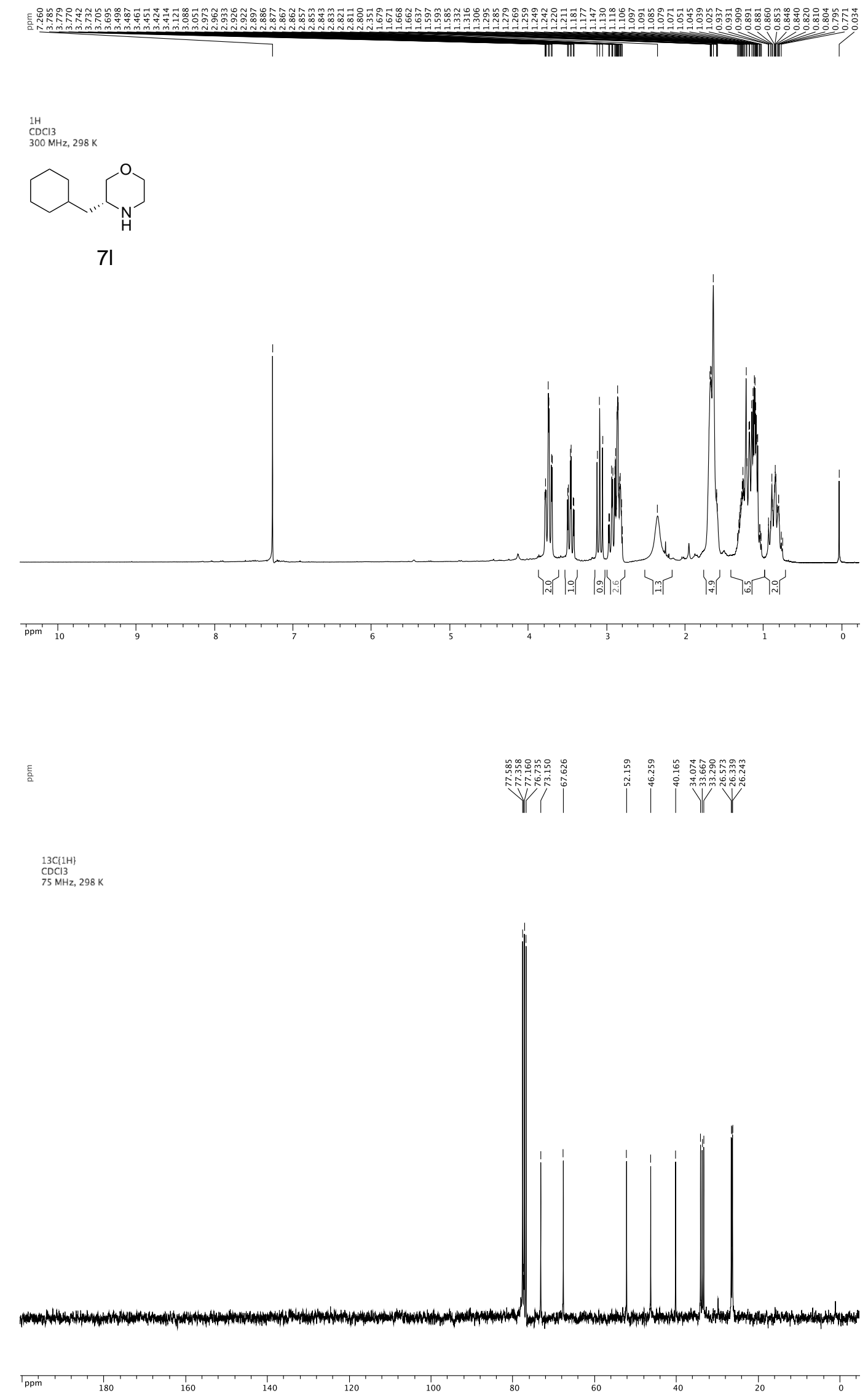
${ }_{\mathrm{CDCl}}^{1 \mathrm{H}}$

$300 \mathrm{MHz}, 298 \mathrm{~K}$<smiles>CN1CCOCC1CC1CCCCC1</smiles>

7I-Ts

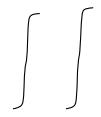

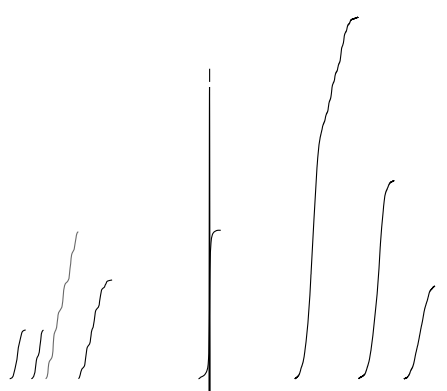
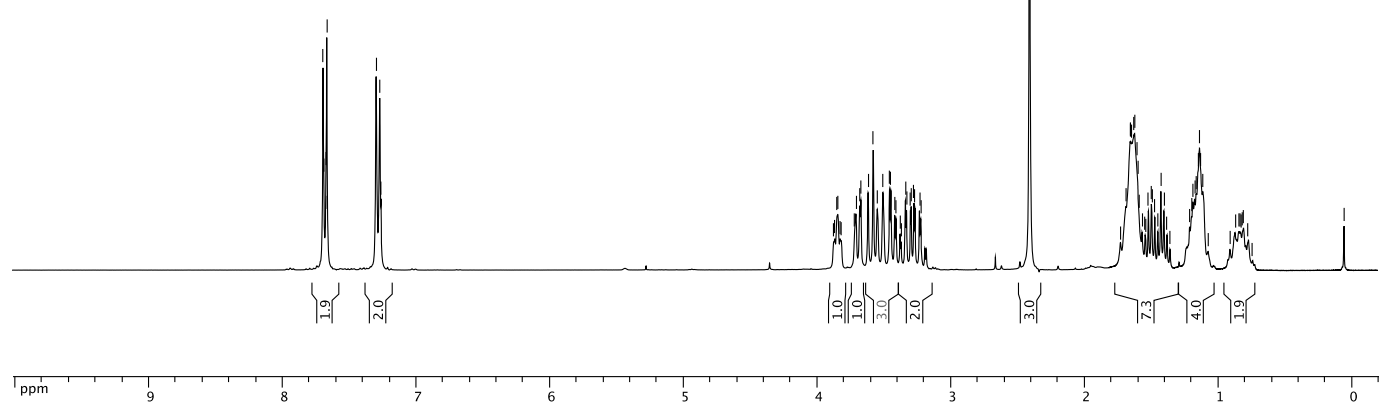

틀

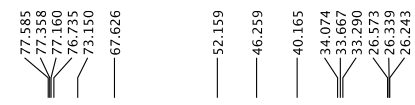

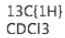

${ }_{75}^{\mathrm{CDCl}} \mathrm{MHz}, 298 \mathrm{~K}$

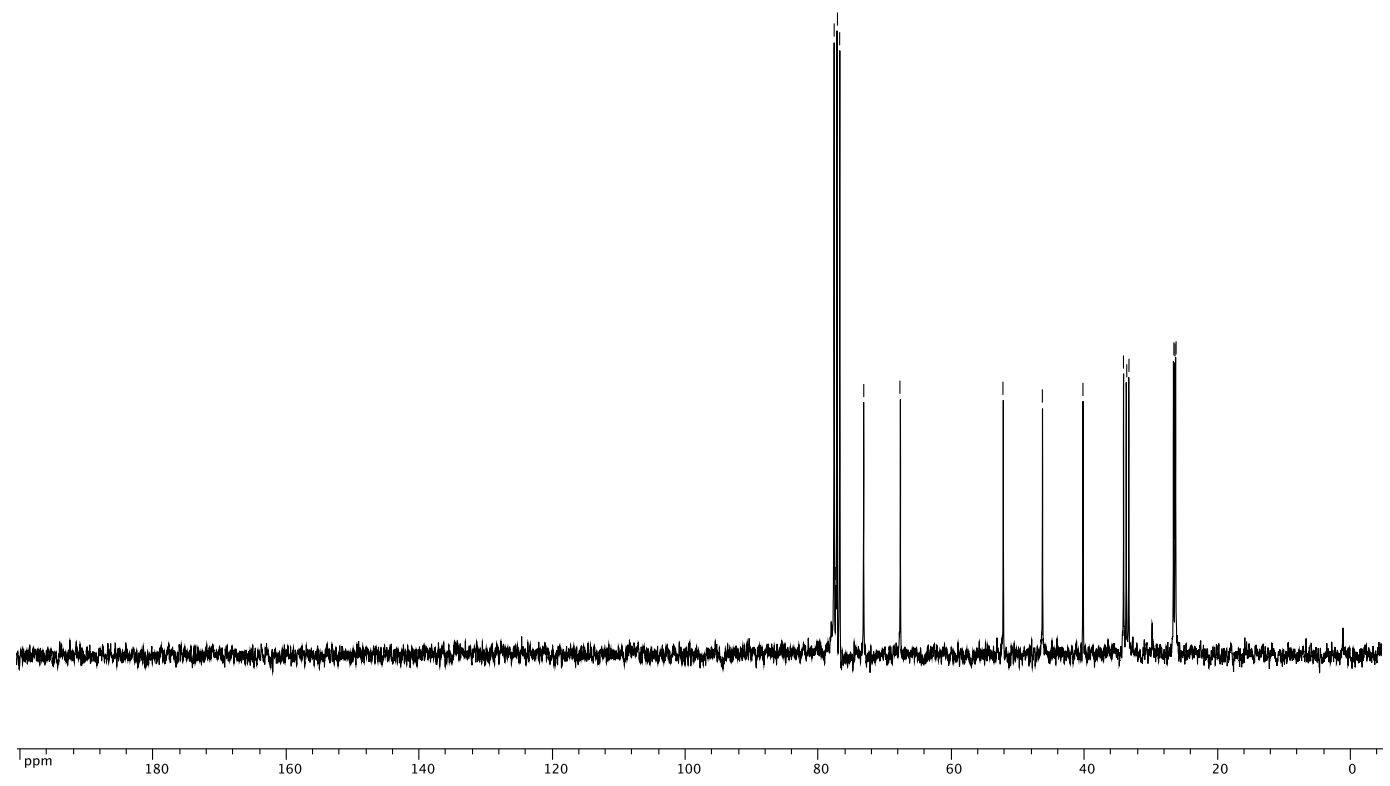




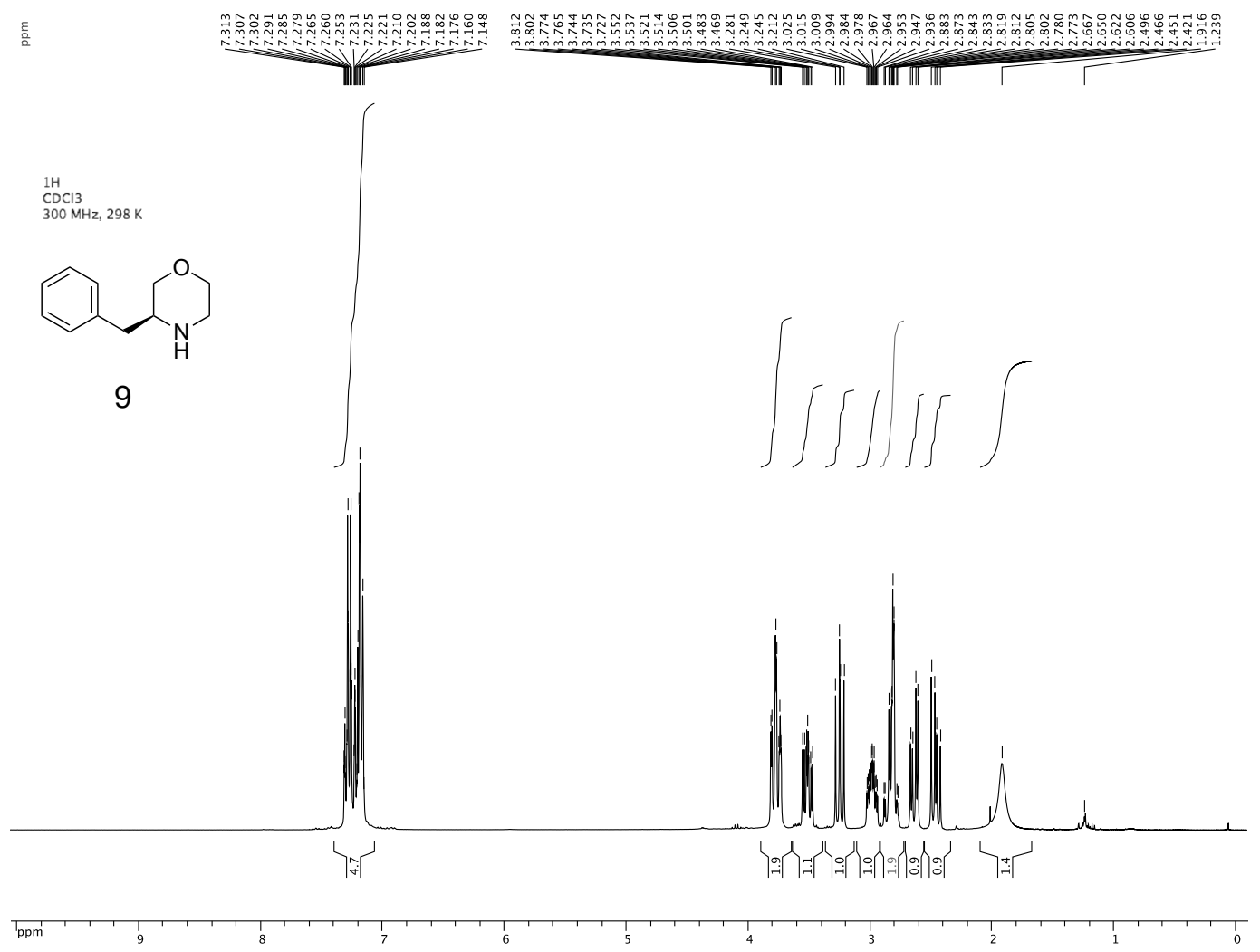



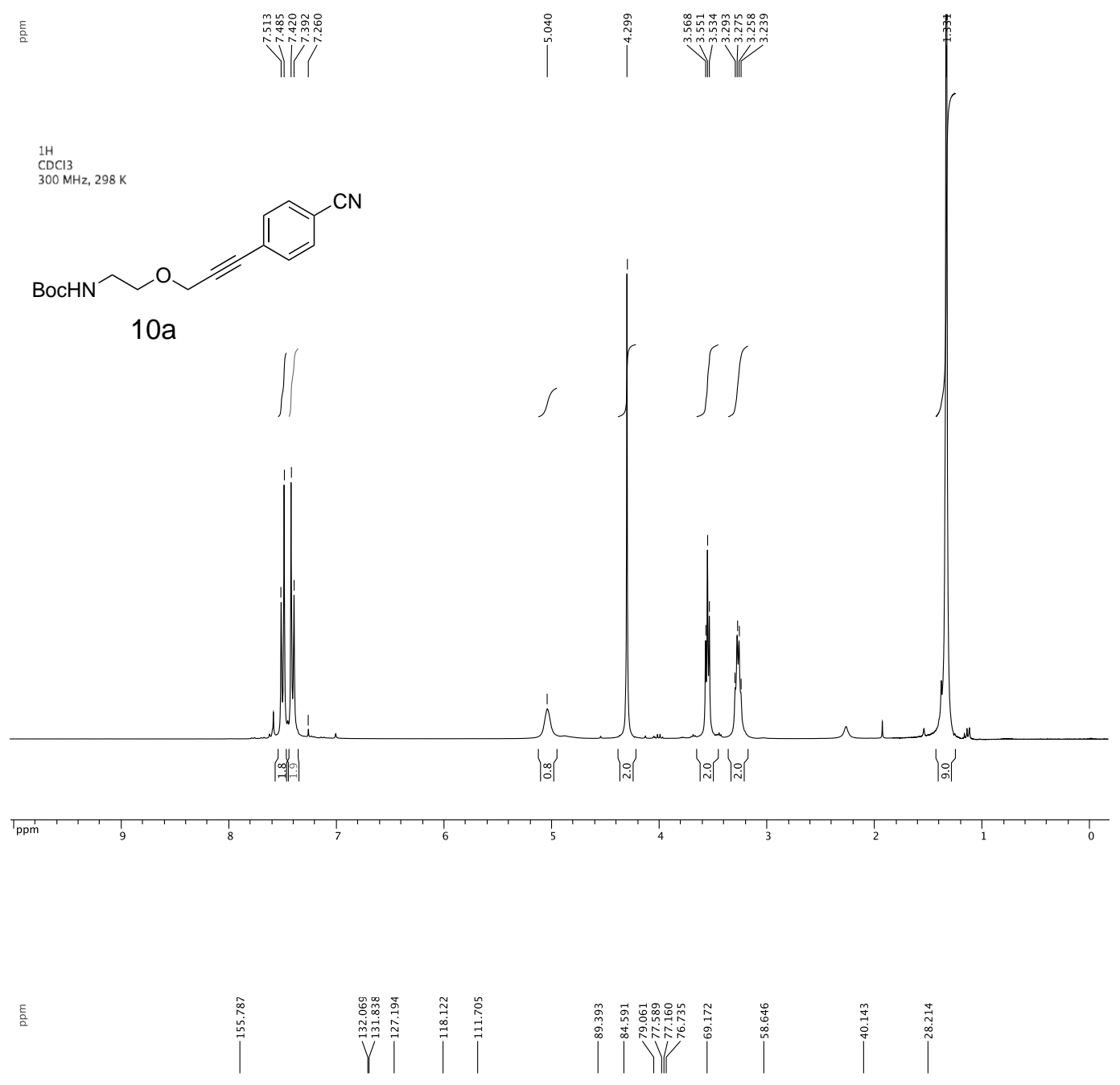

$13 \mathrm{C}\{1 \mathrm{H}\}$
$\mathrm{CDCl}\}$
$75 \mathrm{MHz}, 298 \mathrm{~K}$
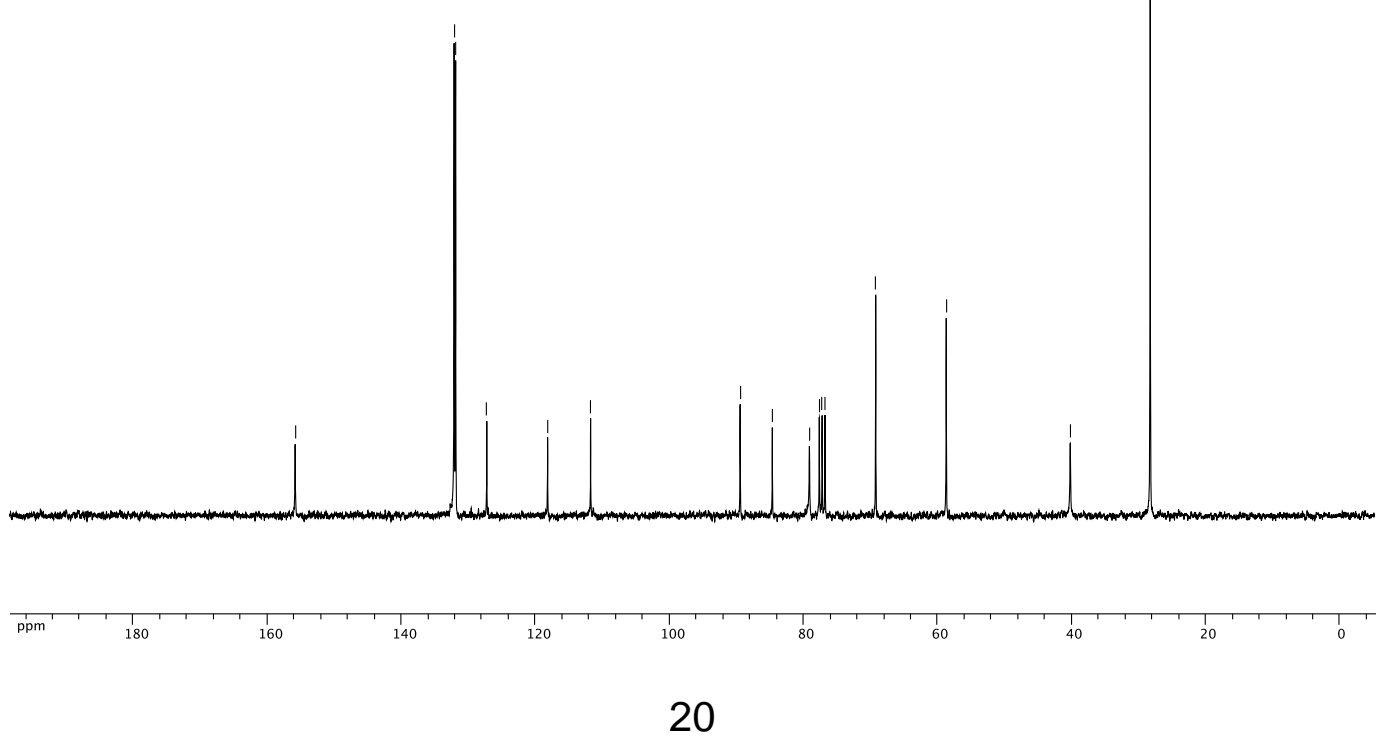

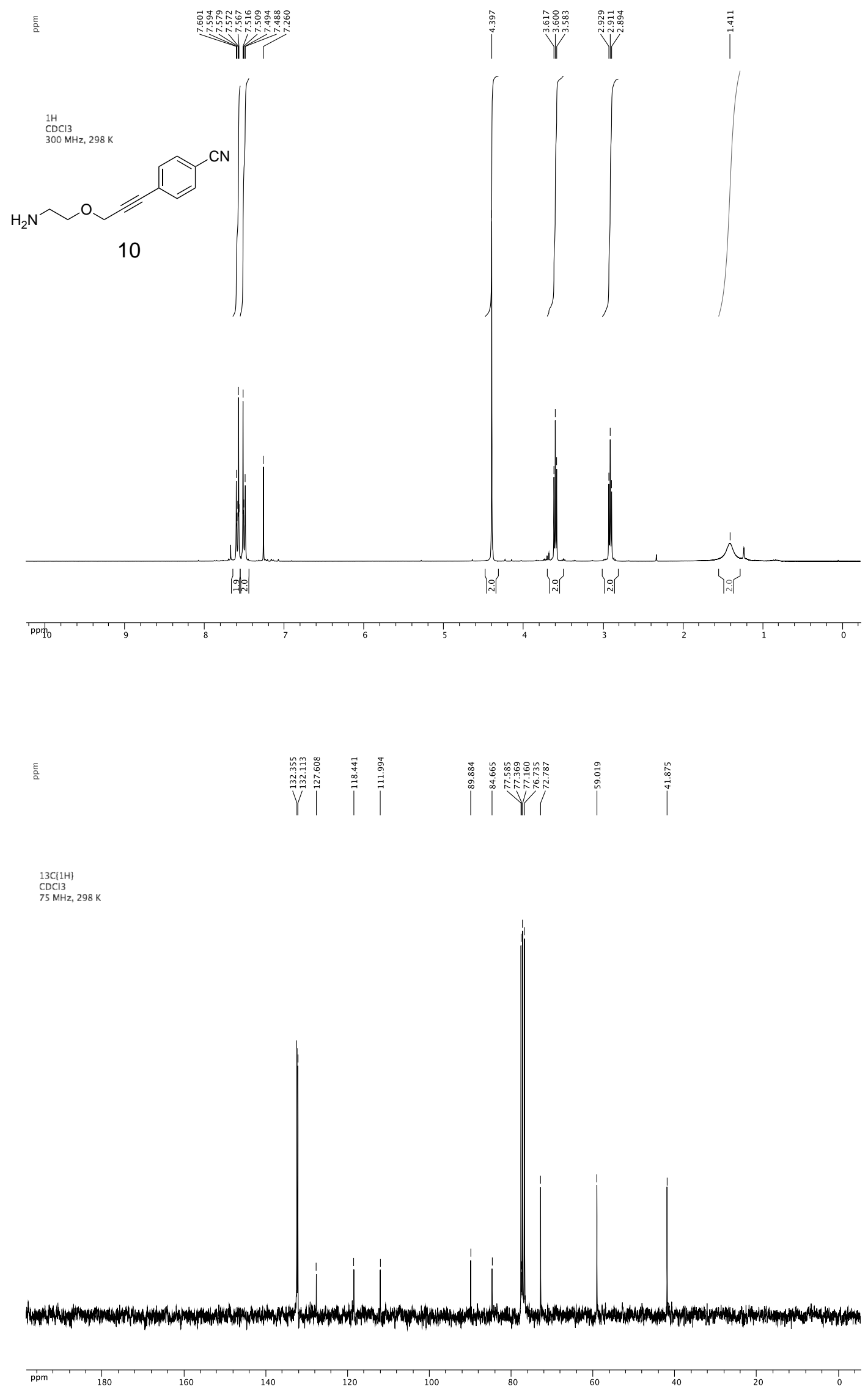

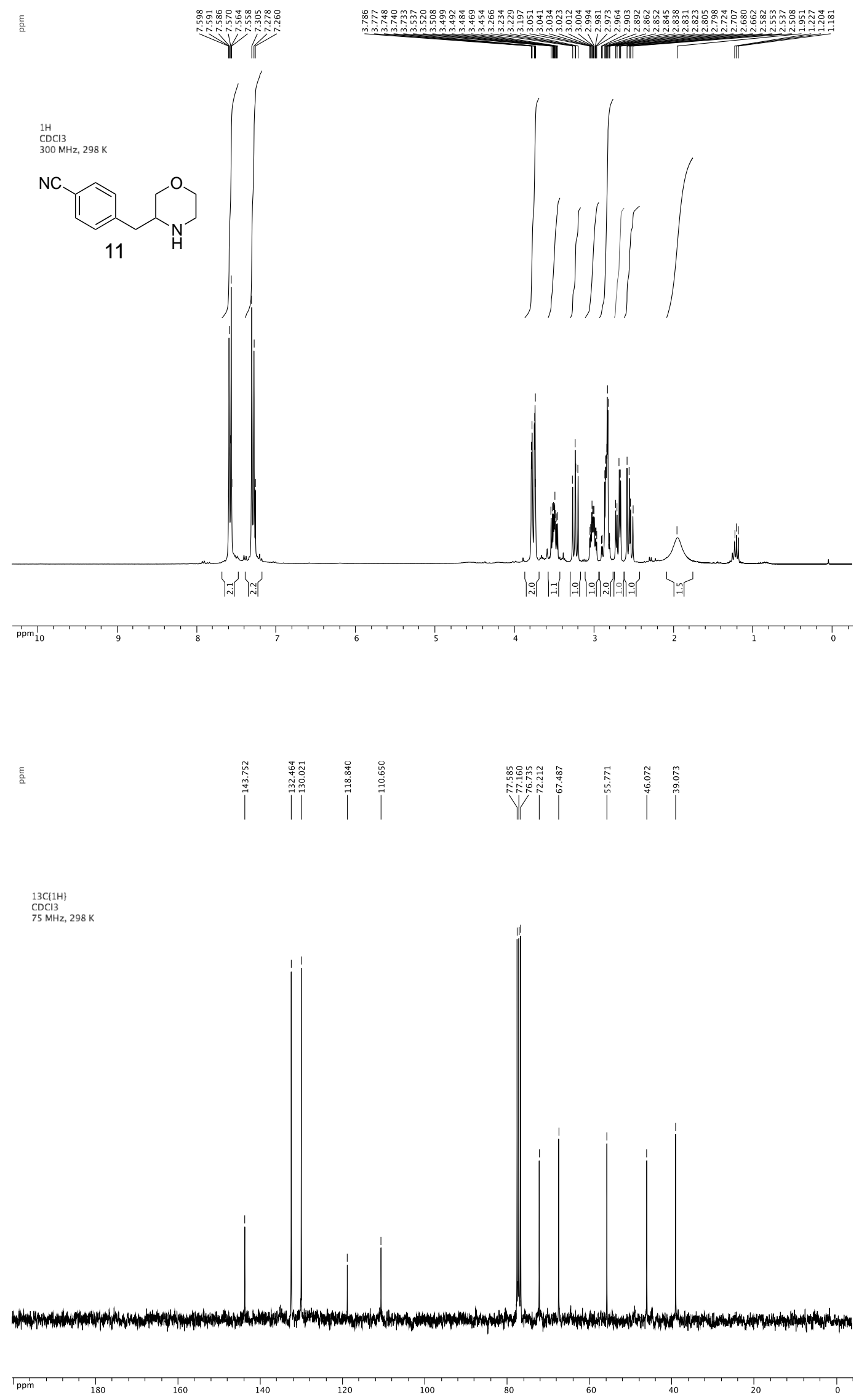

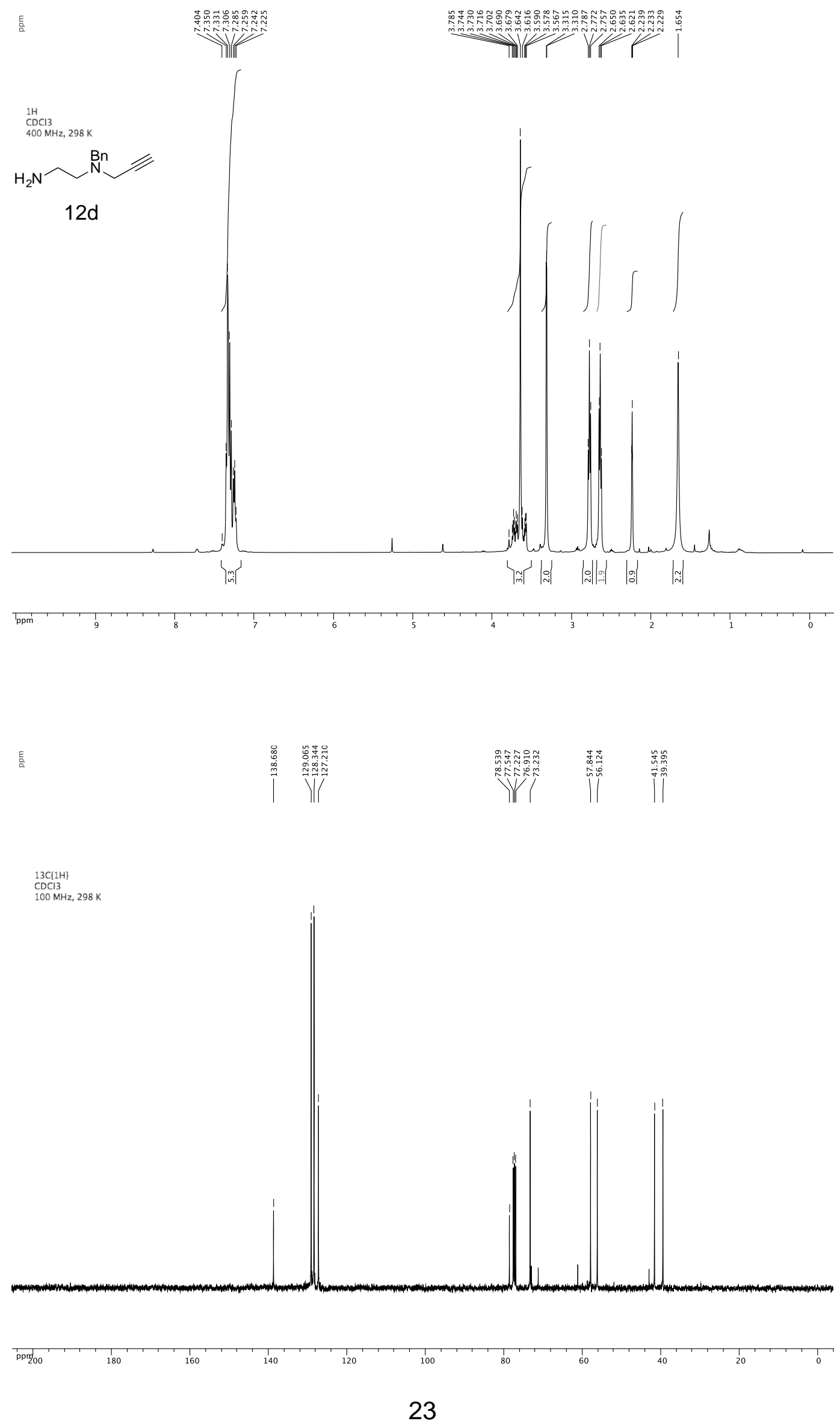


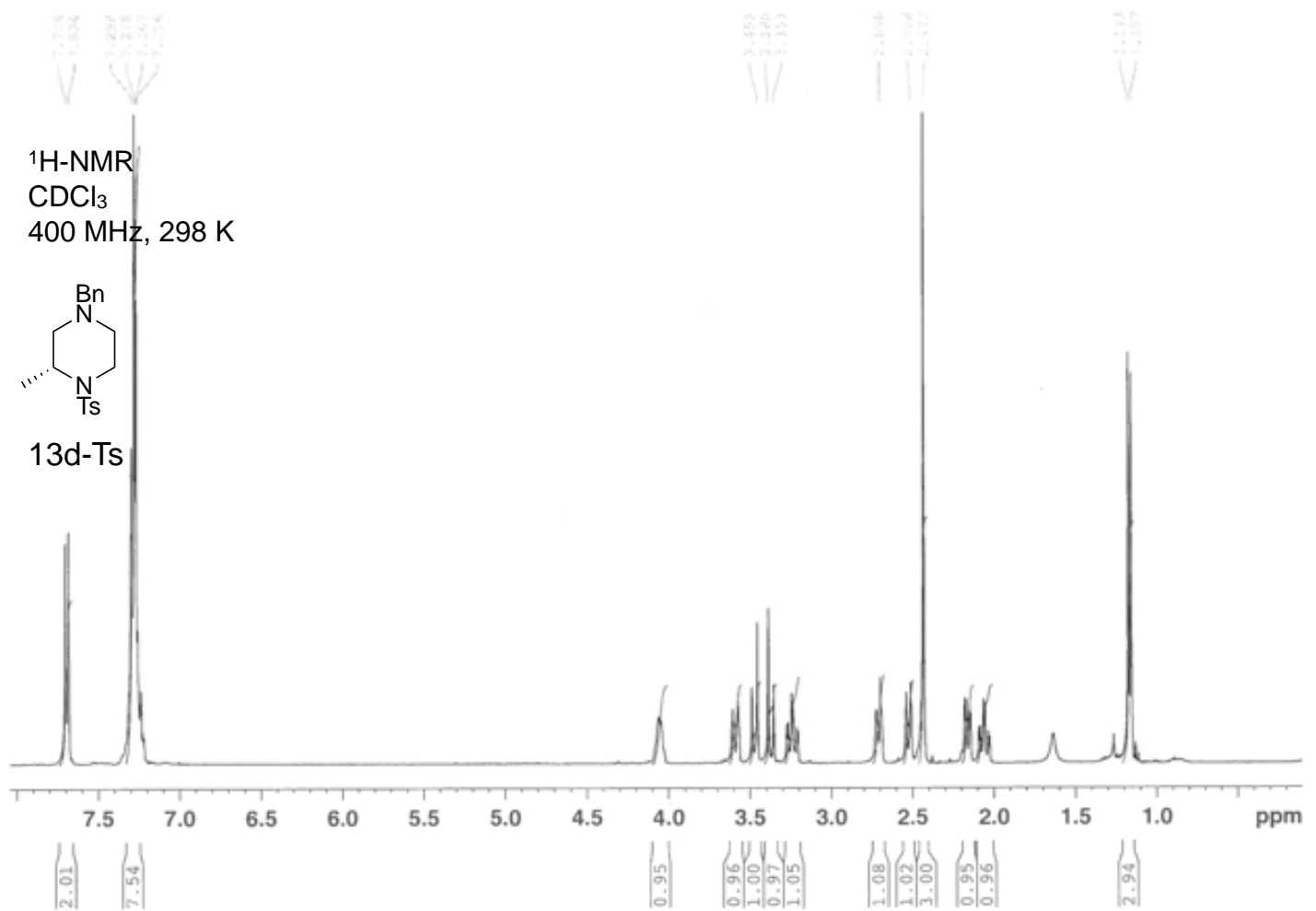

$13 \mathrm{C}$

${ }^{13} \mathrm{C}-\mathrm{NMR}$

$\mathrm{CDCl}_{3}$

$100 \mathrm{MHz}, 298 \mathrm{~K}$

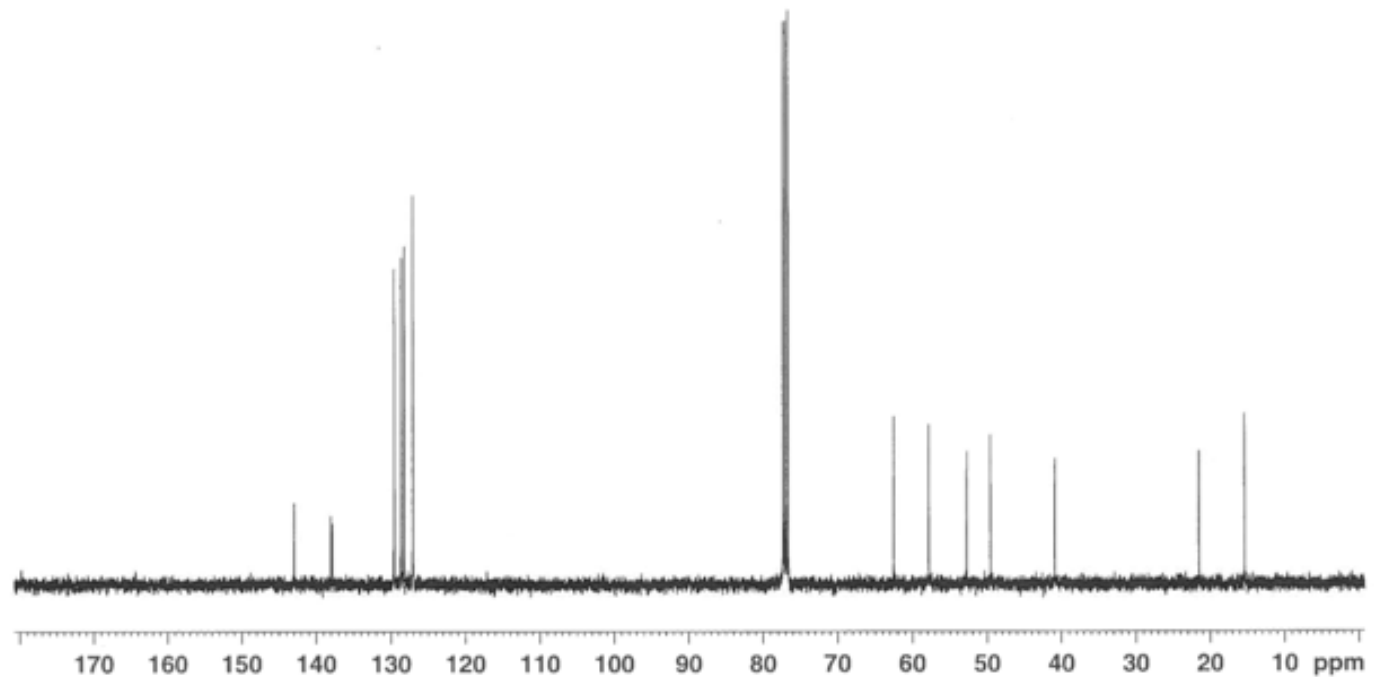


$19 \mathrm{~F}$
CDCl3

${ }_{282}^{\mathrm{CDCl}} \mathrm{MHz}, 298 \mathrm{~K}$

C6F6

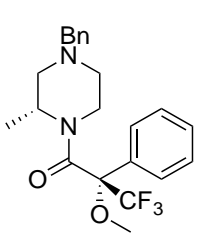

13d-Derivatized
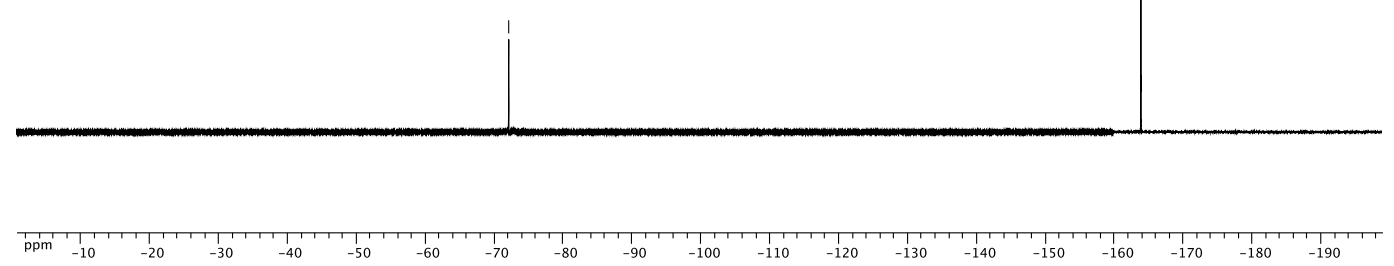

틈
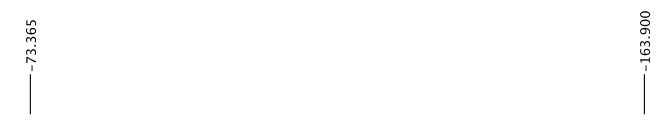

${ }^{19 F}$

$282 \mathrm{MHz}, 298 \mathrm{~K}$

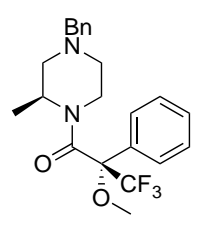

Derivatized enantiomer of $13 d$
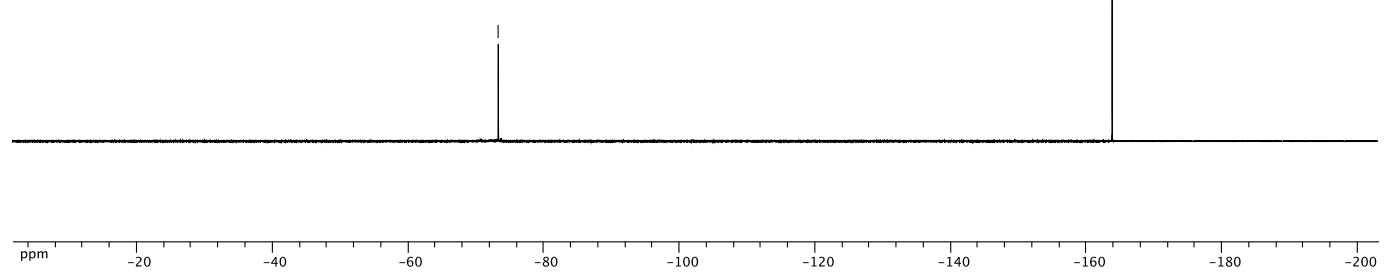

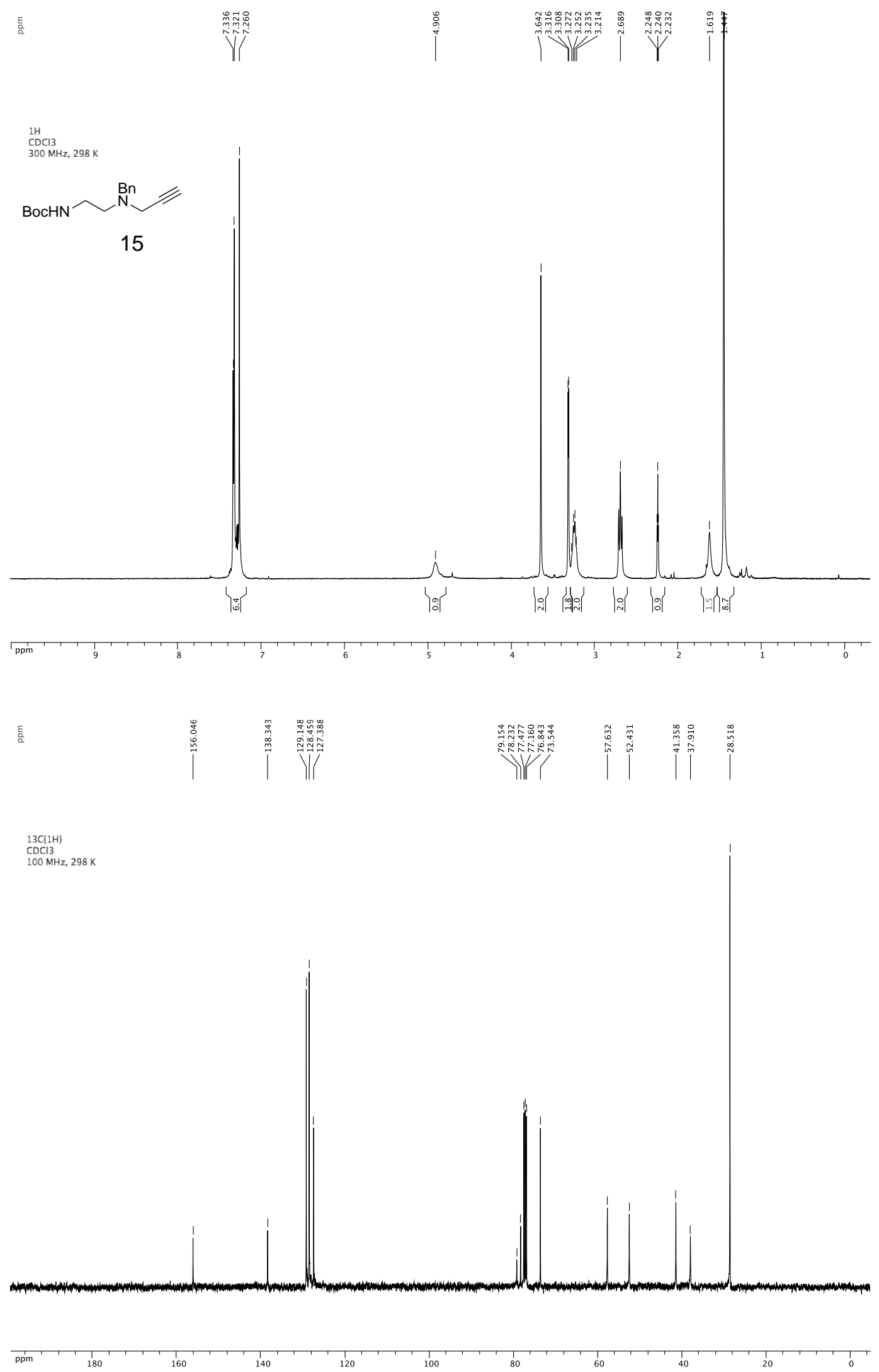

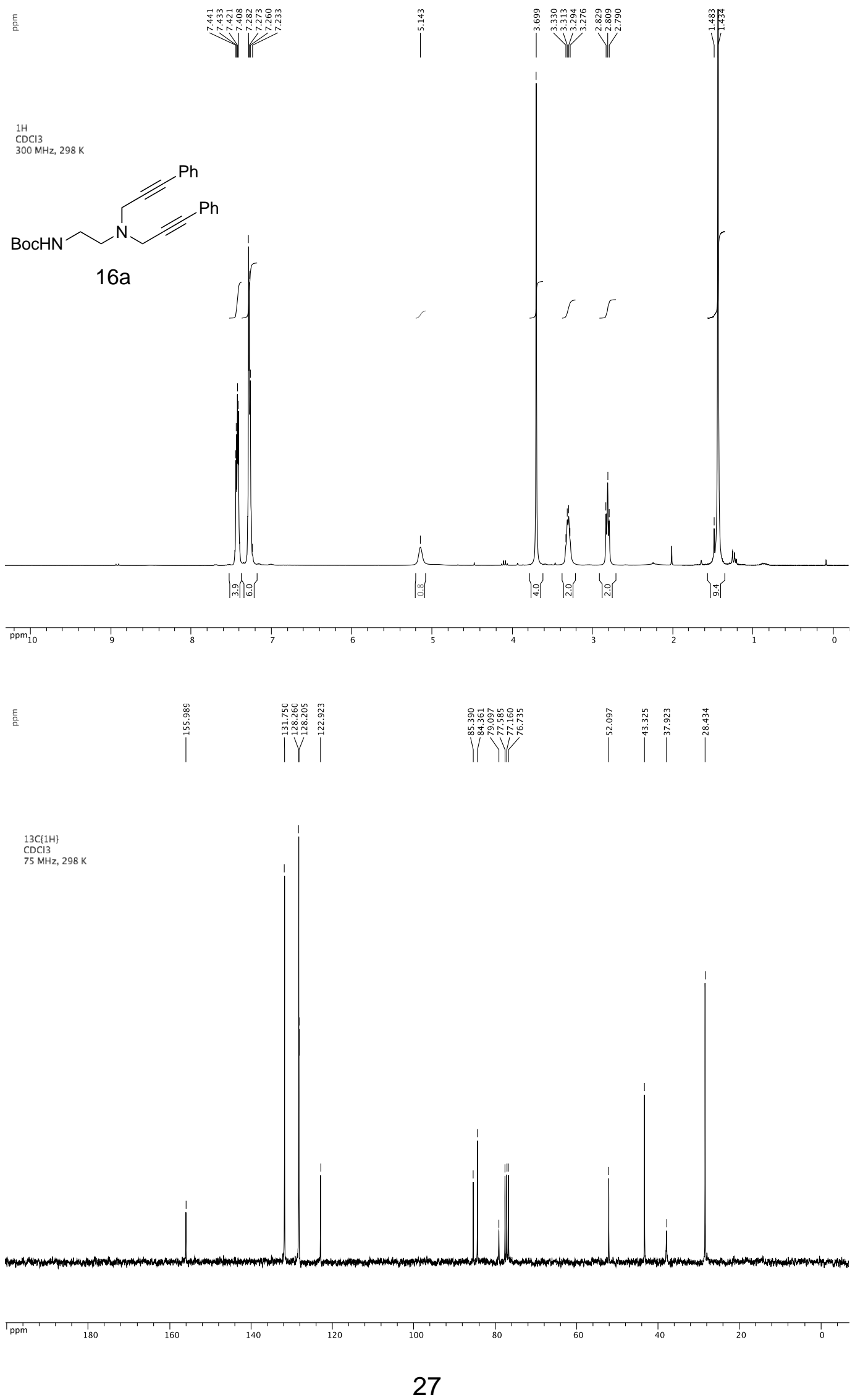

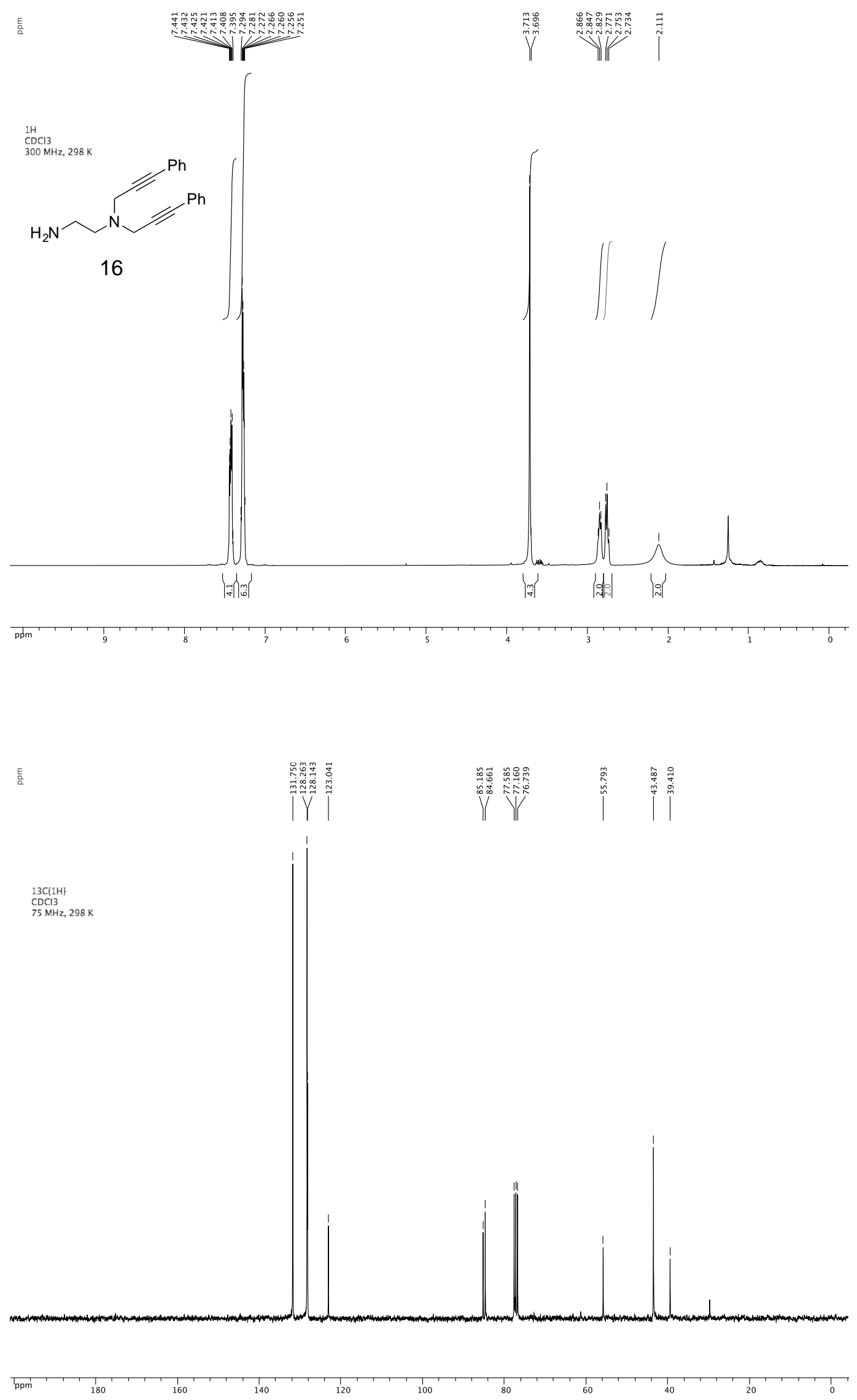


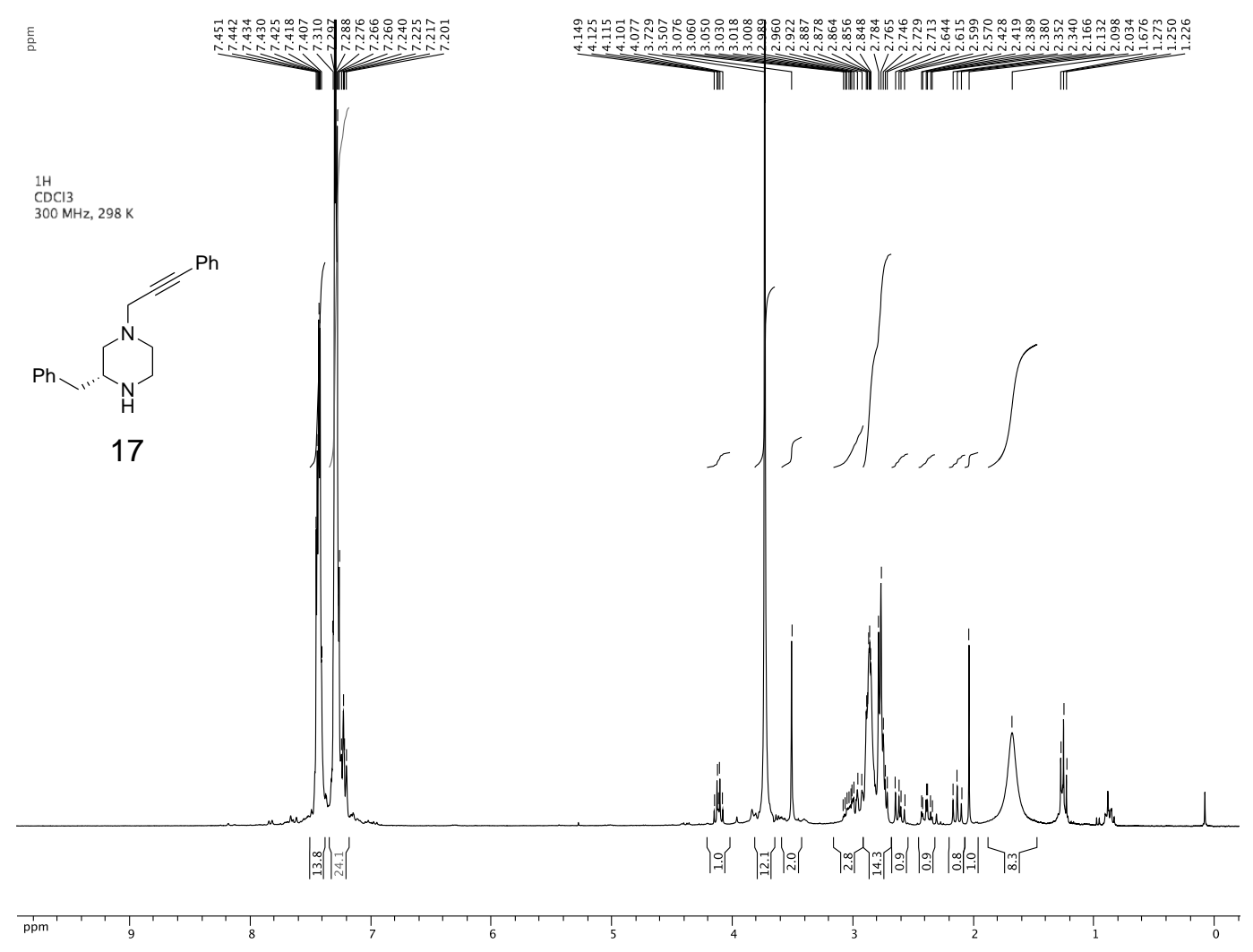




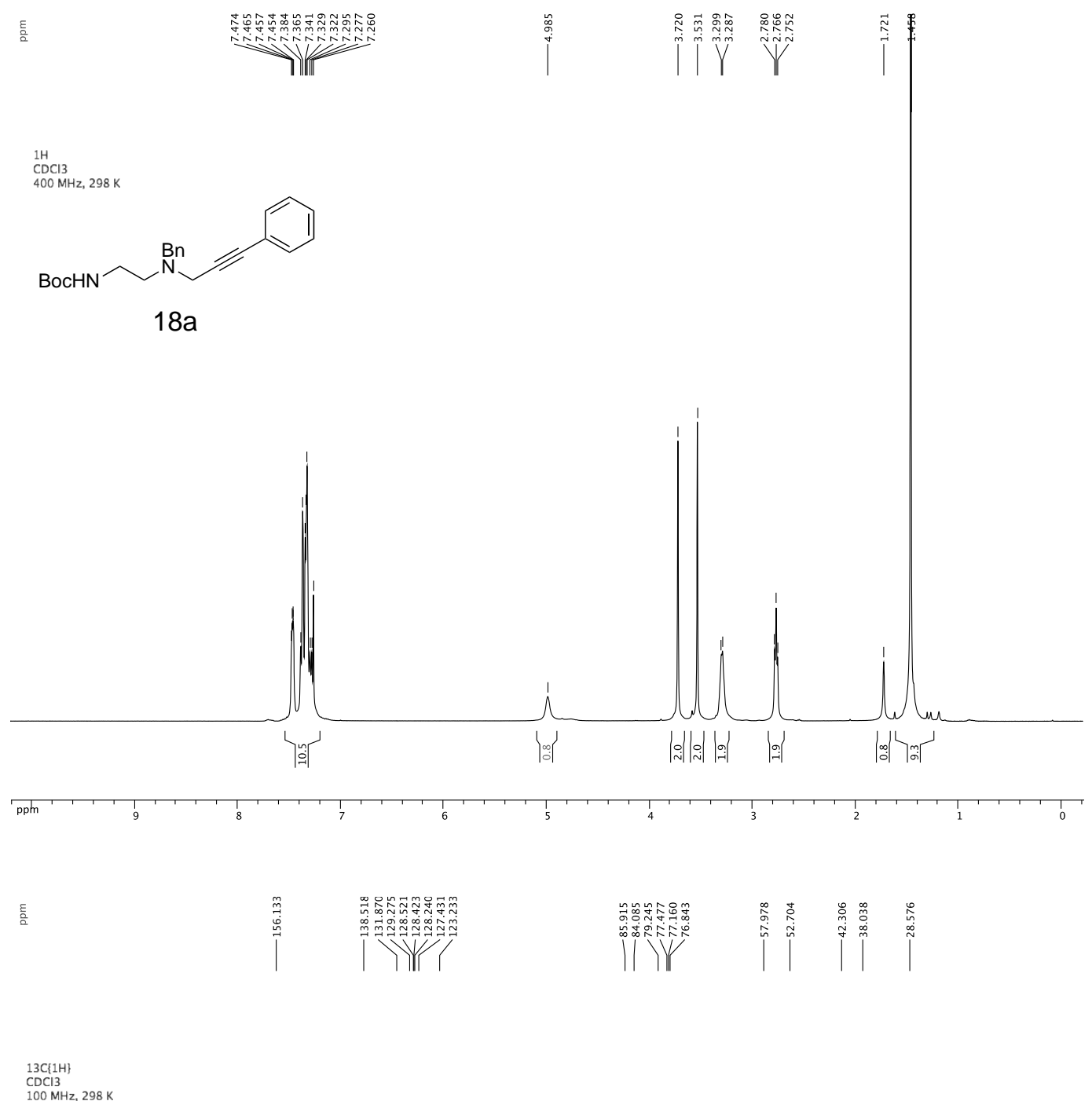

$100 \mathrm{MHz}, 298$
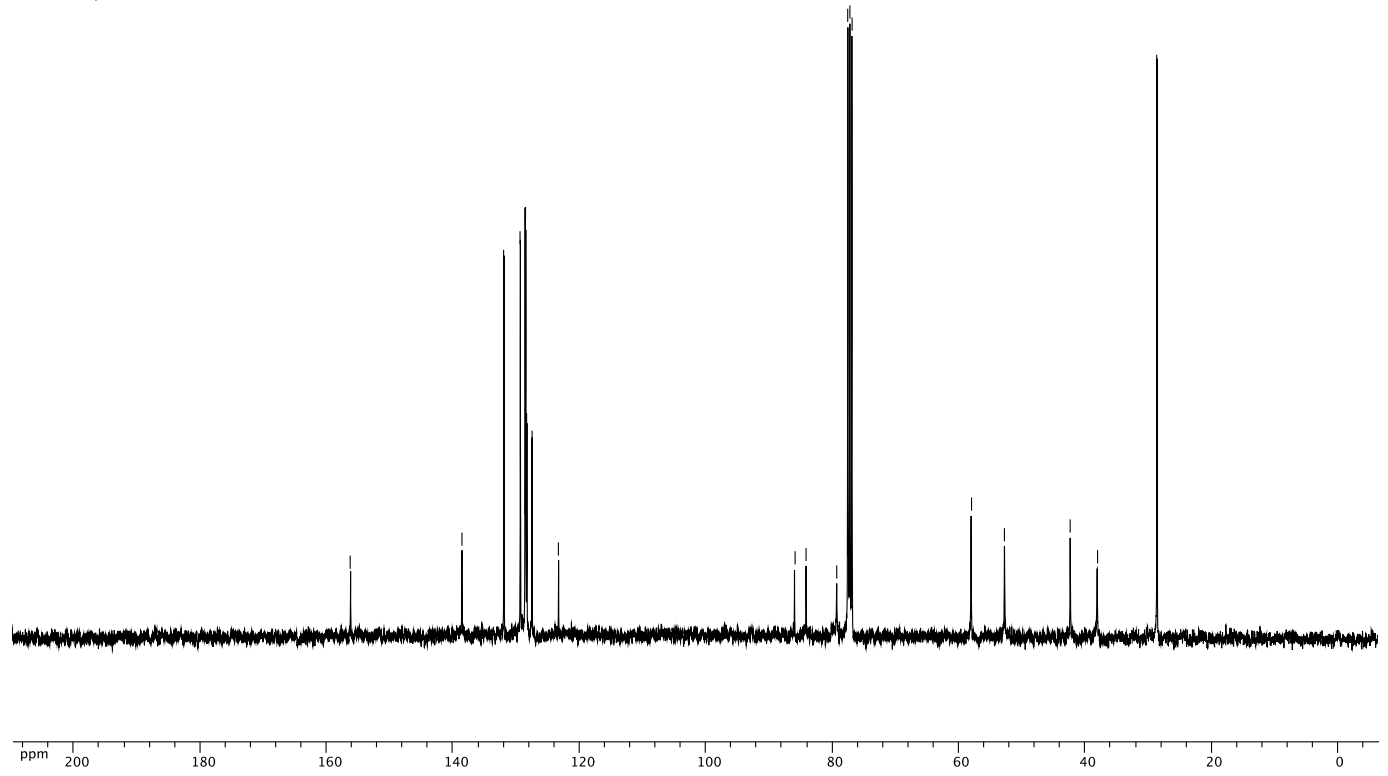

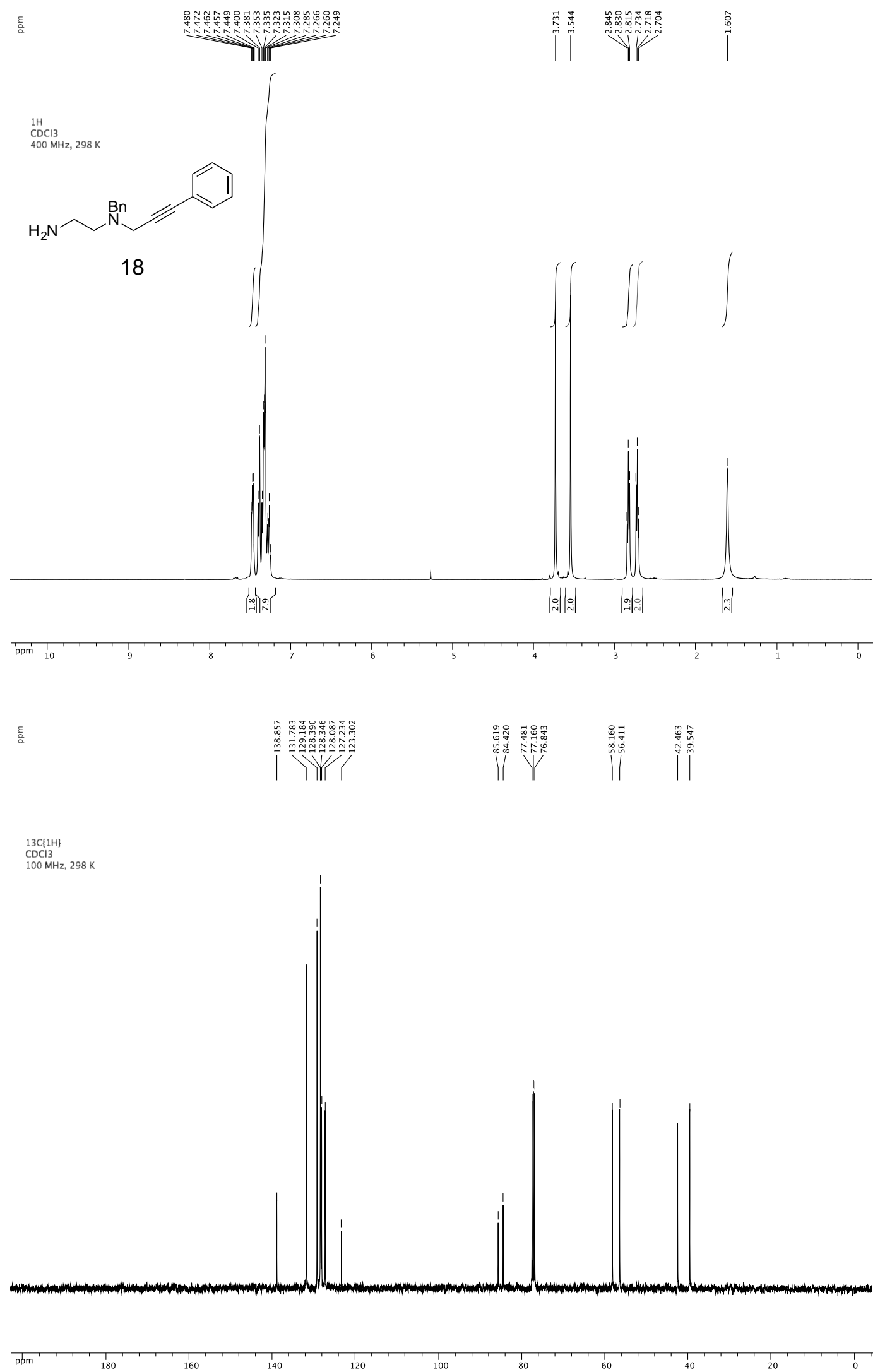

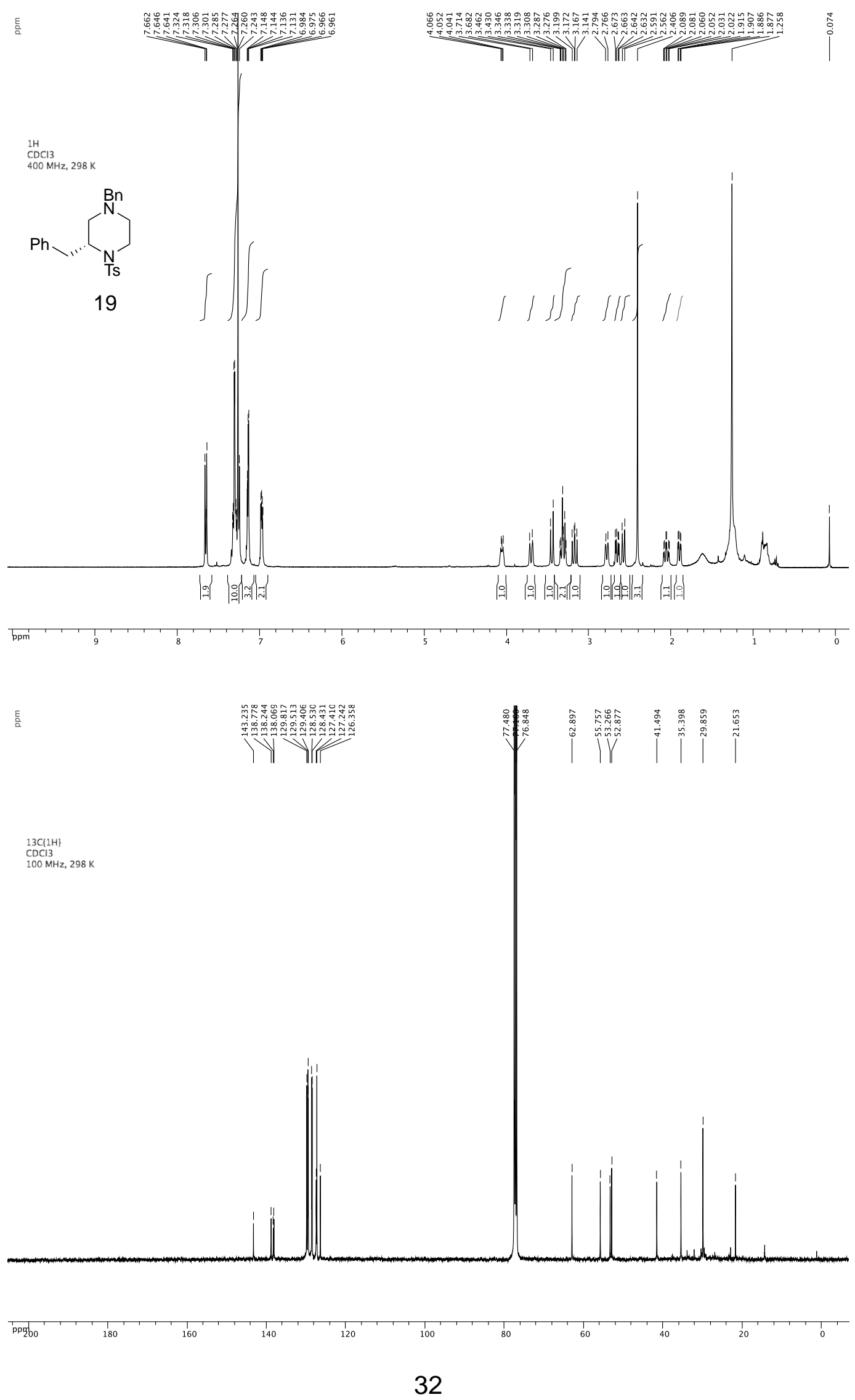


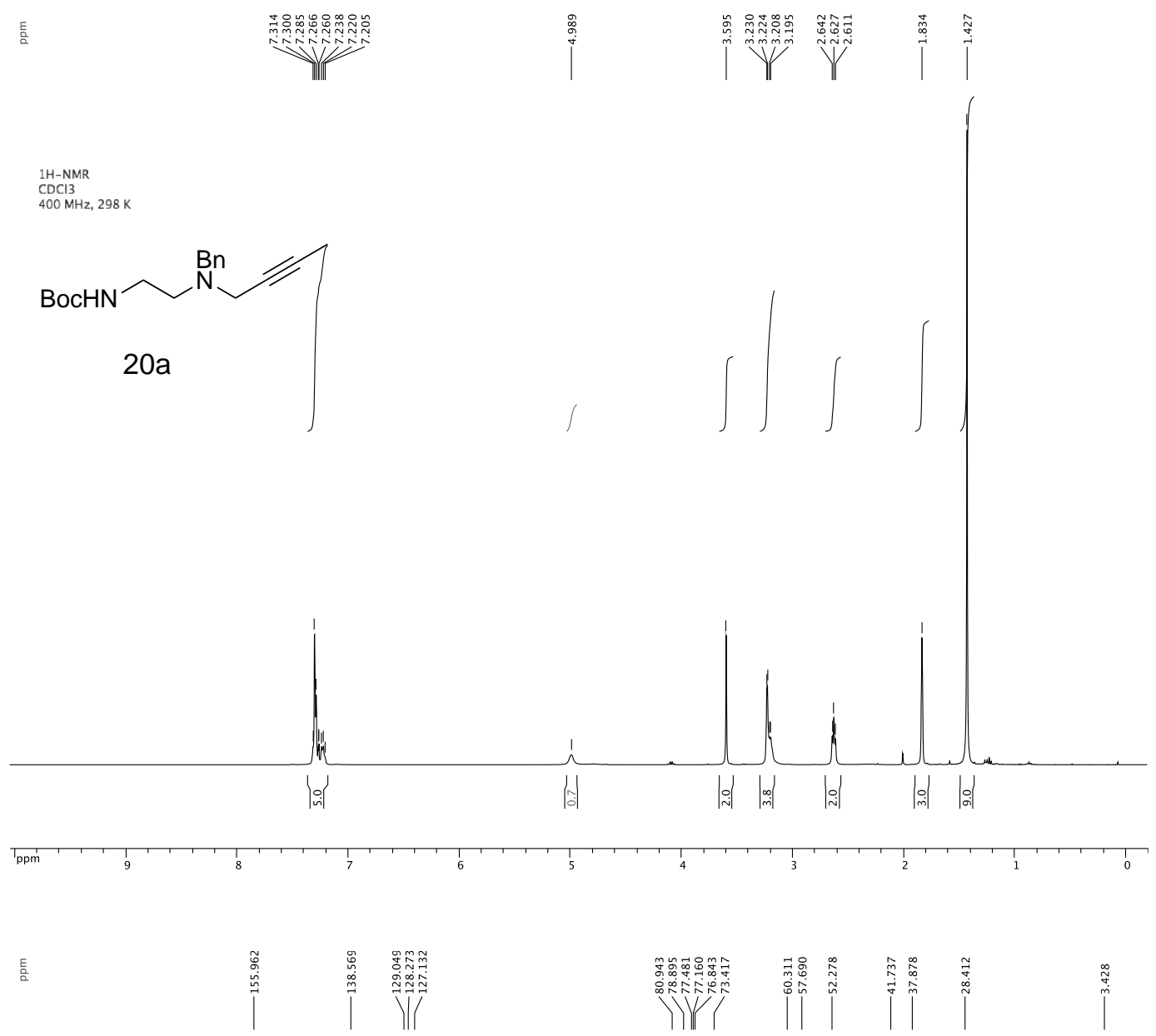

\section{$13 C(1 \mathrm{H})$
$\mathrm{CDCl} 3$}

$100 \mathrm{MHz}, 298 \mathrm{~K}$
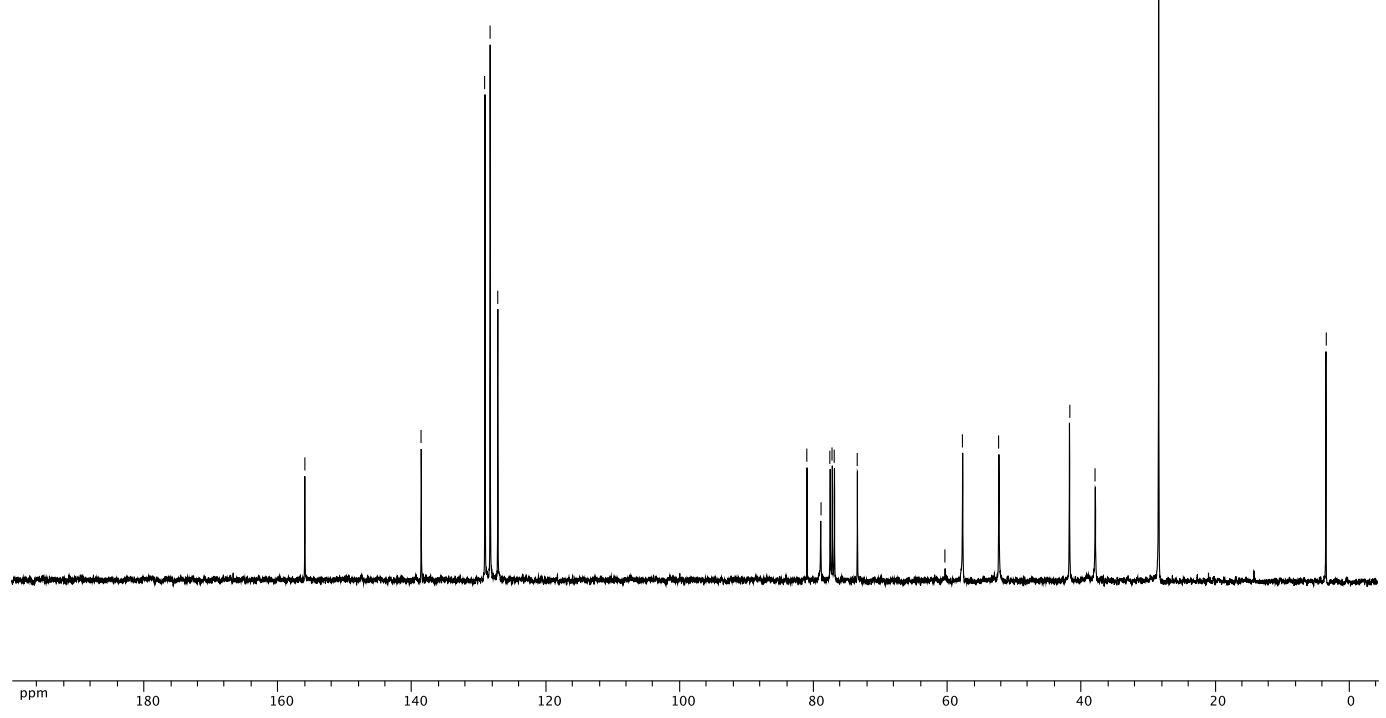

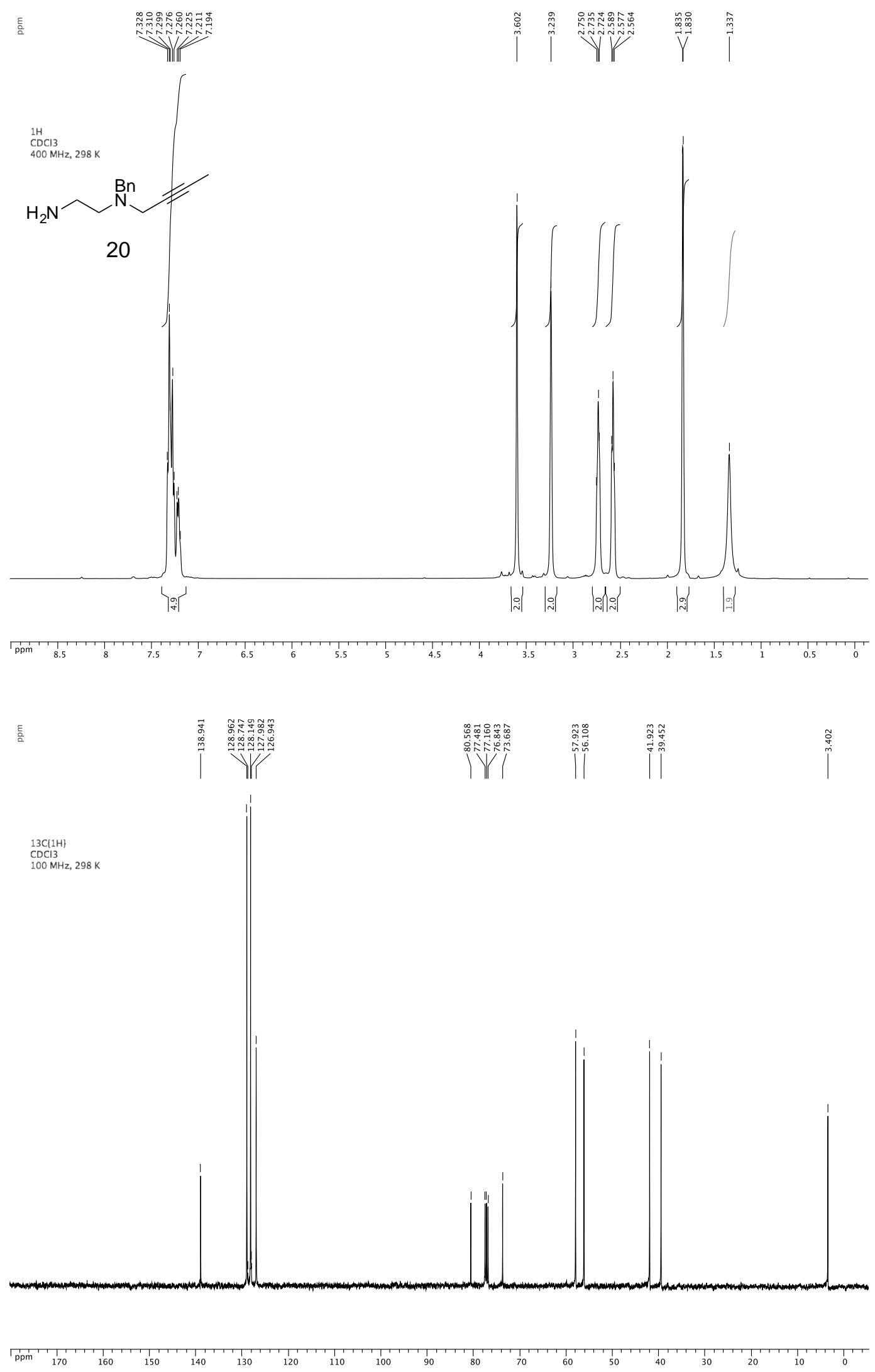

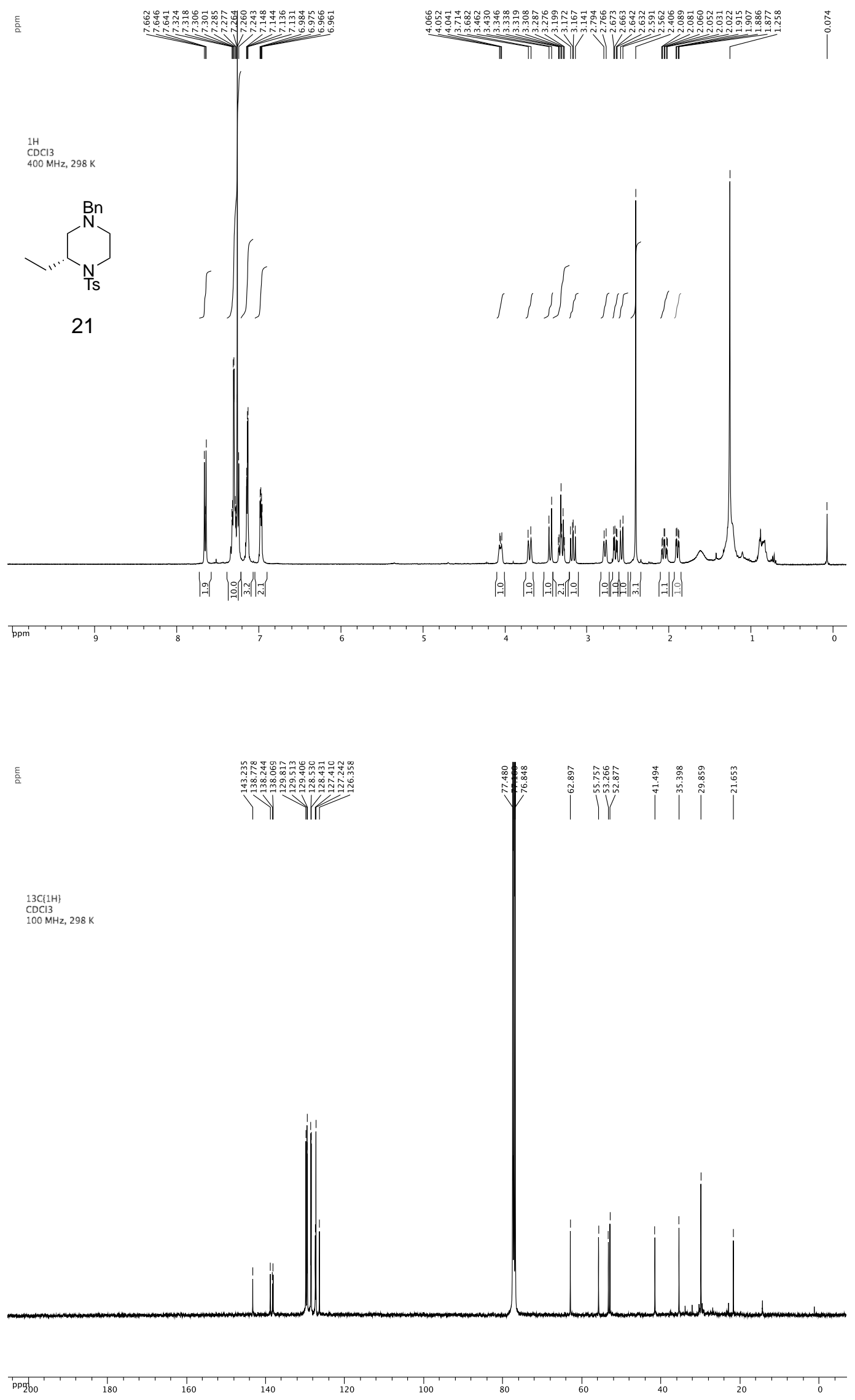
Enantiomeric Excess Determination of Compound 7c

SFC Trace of Racemic 7c

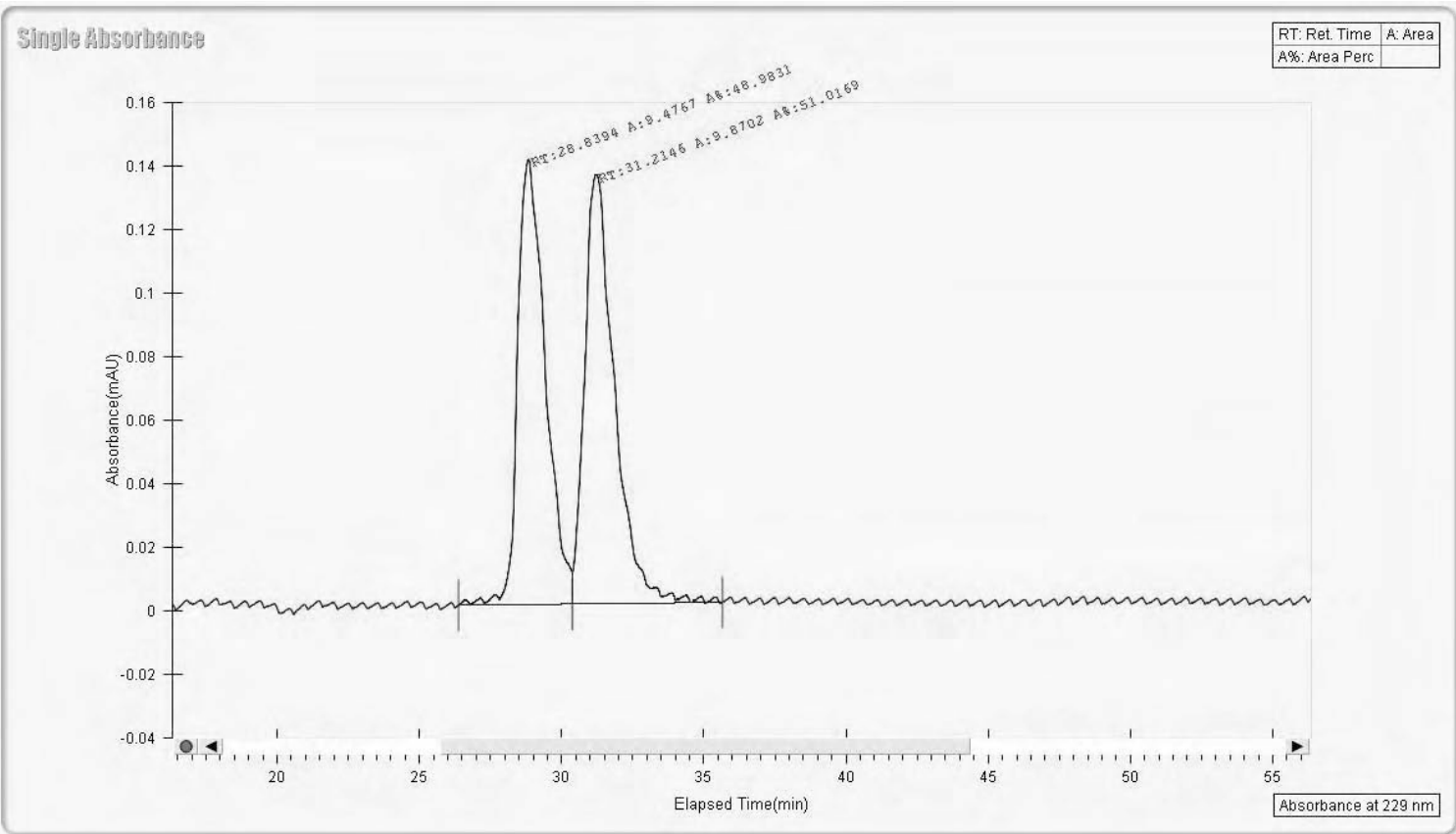

SFC Trace of (R)-3-(4-(trifluoromethyl)benzyl)morpholine (7c)

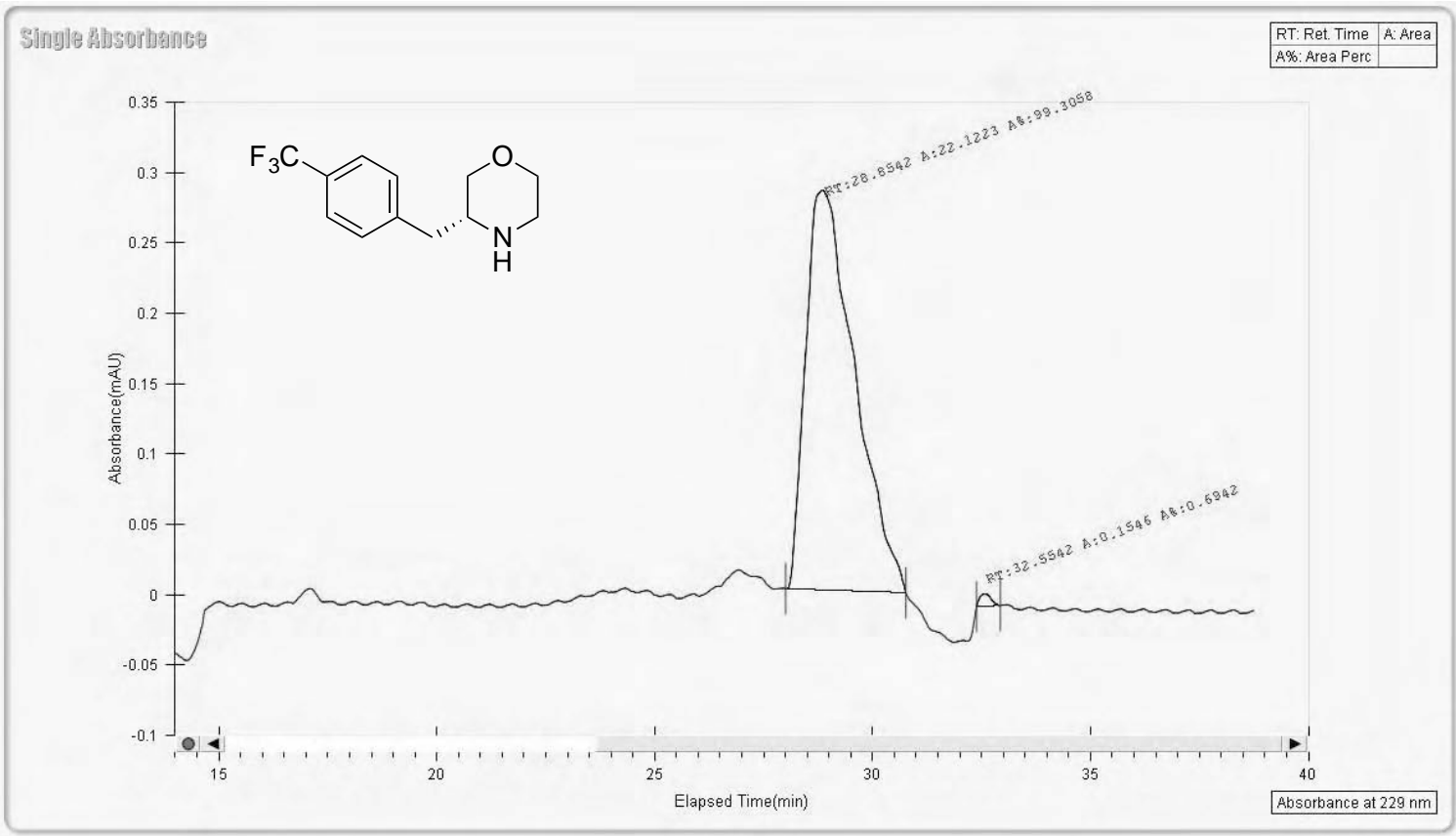

Thar SFC AD-H column $0.46 \mathrm{~cm} \times 25 \mathrm{~cm} 5 \mu \mathrm{m}$

Mobile phase: liq. $\mathrm{CO}_{2} / 2$-propanol/diethylamine, 97:3:0.1

Flow rate $1.0 \mathrm{~mL} / \mathrm{min} \mathrm{UV} 229 \mathrm{~nm}$ 


\section{Enantiomeric Excess Determination of Compound 7e}

SFC Trace of Racemic 7e

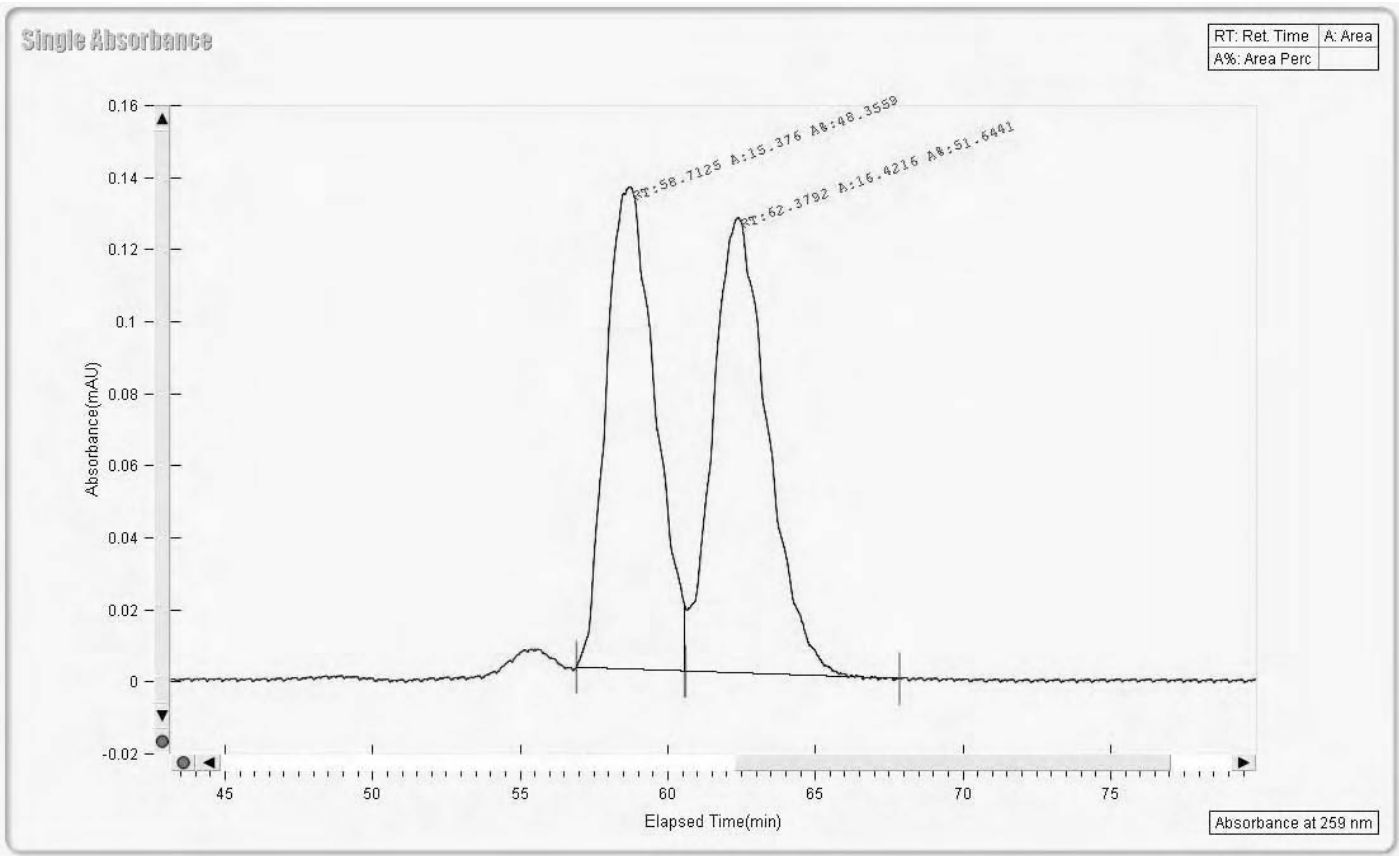

SFC Trace of $(R)$-3-(3-methoxybenzyl)morpholine (7e)

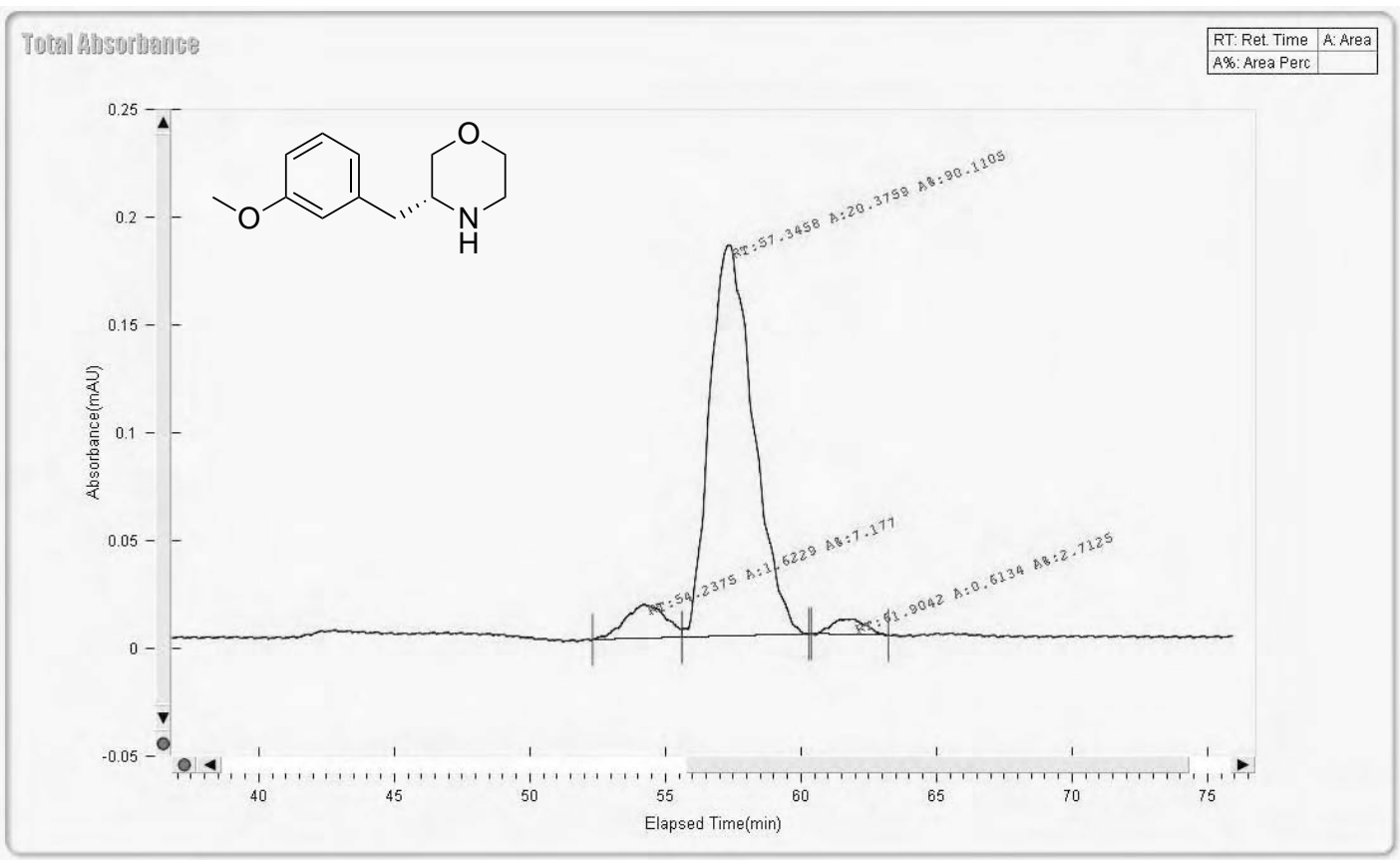

Thar SFC OD-H column $0.46 \mathrm{~cm} \times 25 \mathrm{~cm} 5 \mu \mathrm{m}$

Mobile phase: liq. $\mathrm{CO}_{2}$ /2-propanol/diethylamine, 98:2:0.1 
Enantiomeric Excess Determination of Compound $\mathbf{7 g}$

SFC Trace of Racemic $\mathbf{7 g}$

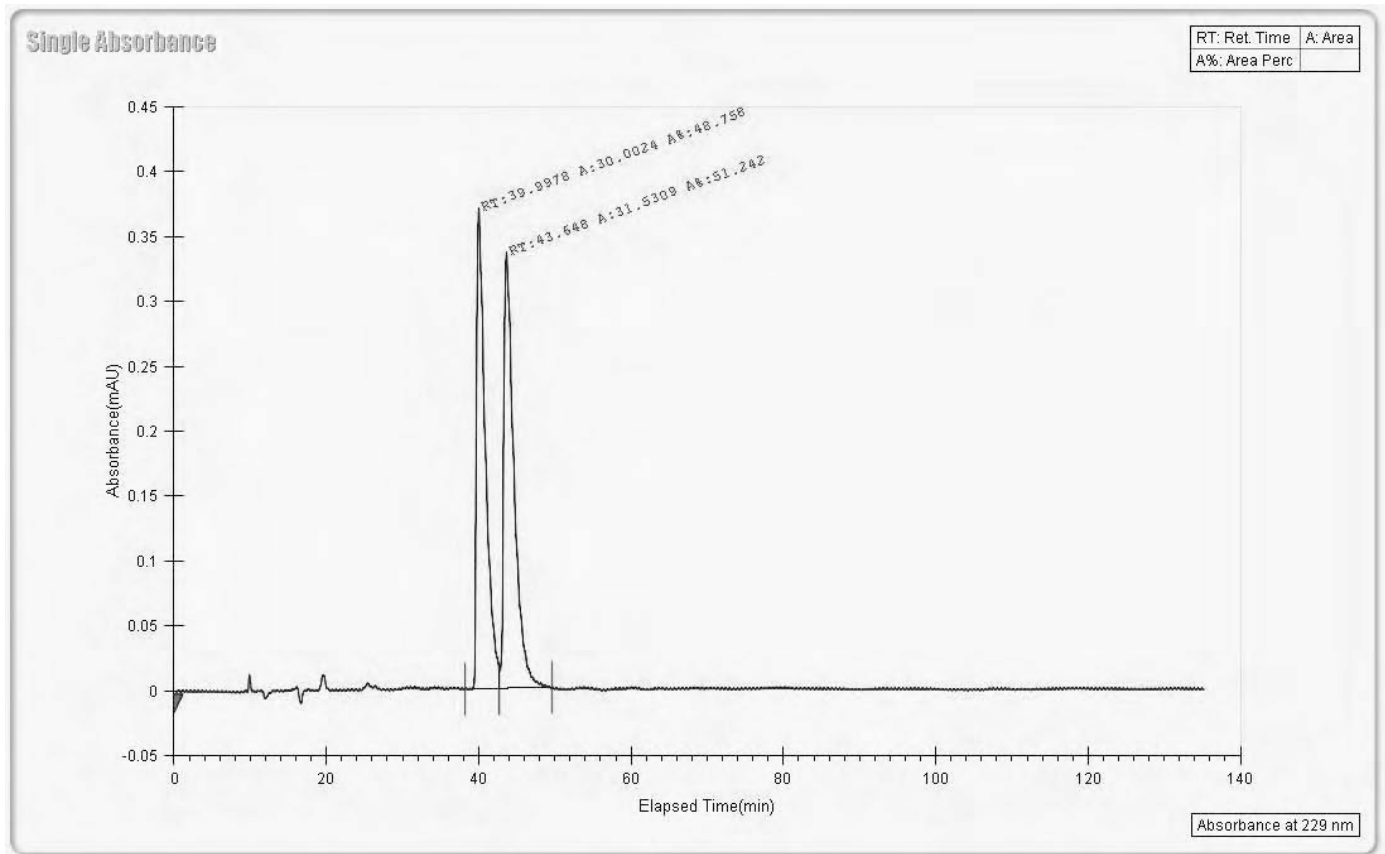

SFC Trace of $(R)$-3-(naphthalen-1-ylmethyl)morpholine (7g)

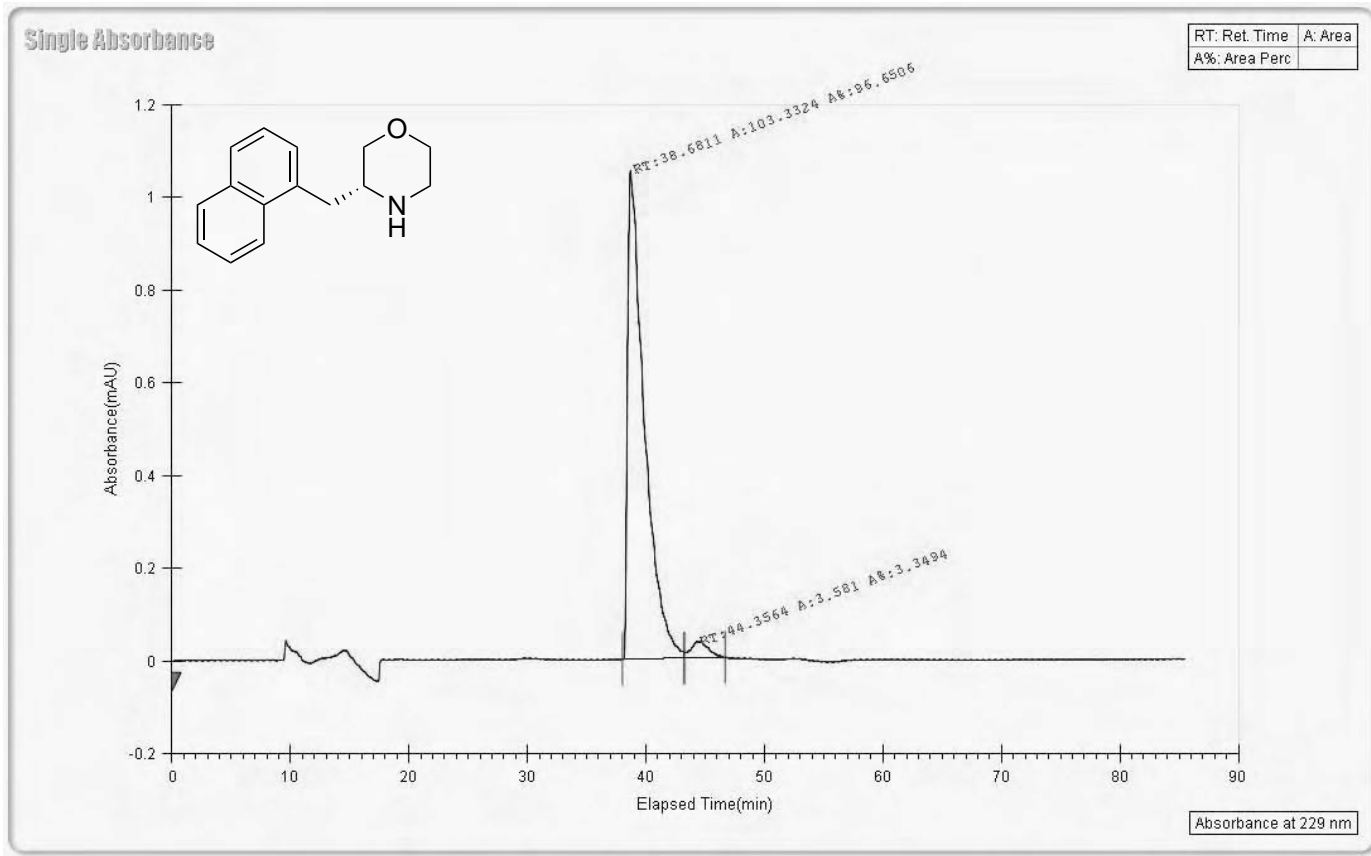

Chiralpak AS-H column $0.46 \mathrm{~cm} \times 25 \mathrm{~cm} 5 \mu \mathrm{m}$

Mobile phase: liq. $\mathrm{CO}_{2} / 2$-propanol/diethylamine, 97:3:0.1

Flow rate $1.0 \mathrm{~mL} / \mathrm{min} \quad$ UV $229 \mathrm{~nm}$ 


\section{Enantiomeric Excess Determination of Compound 7l-Ts}

\section{SFC Trace of Racemic 7l-Ts}

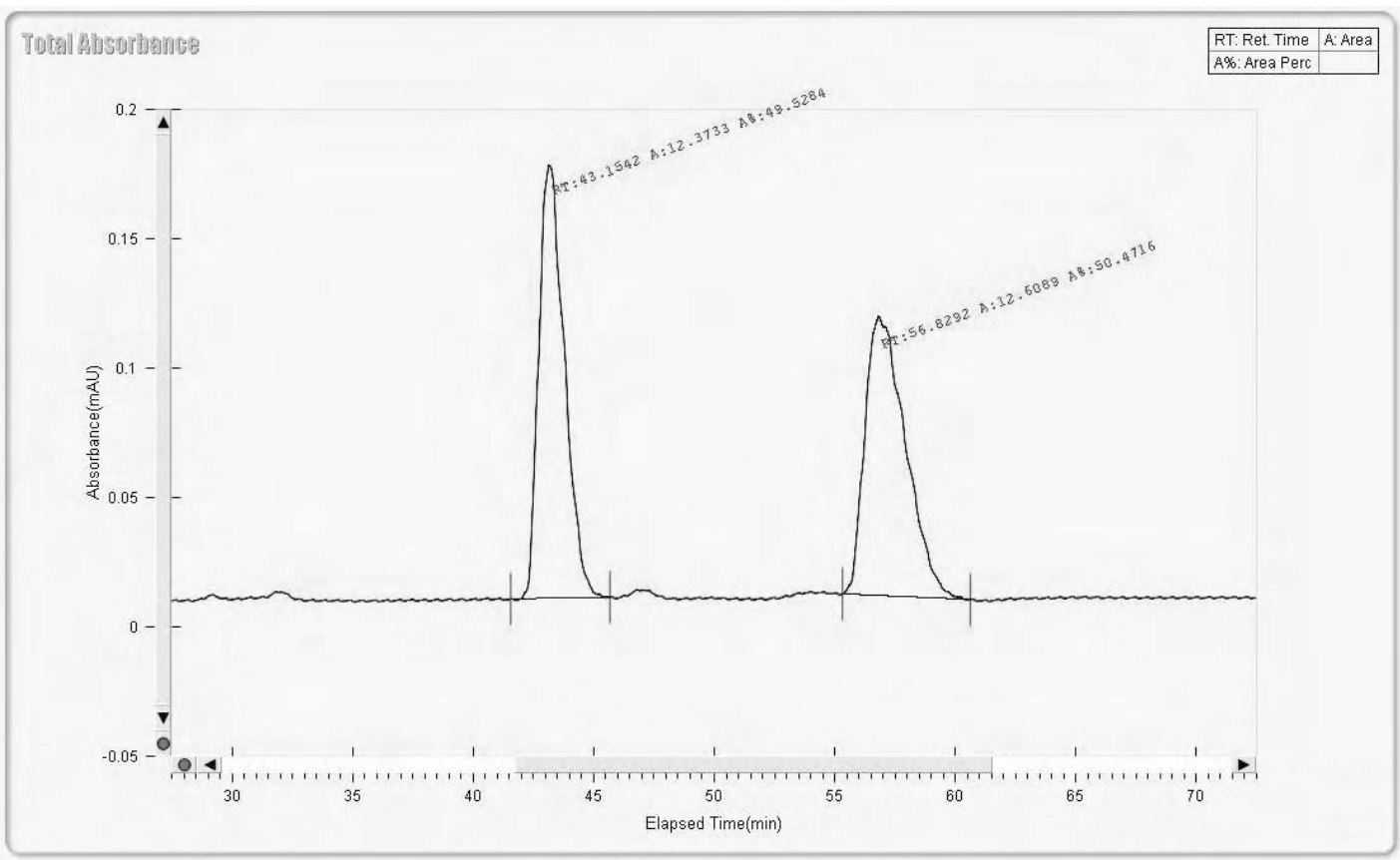

SFC Trace of $(R)$-3-(cyclohexylmethyl)-4-tosylmorpholine (7l-Ts)

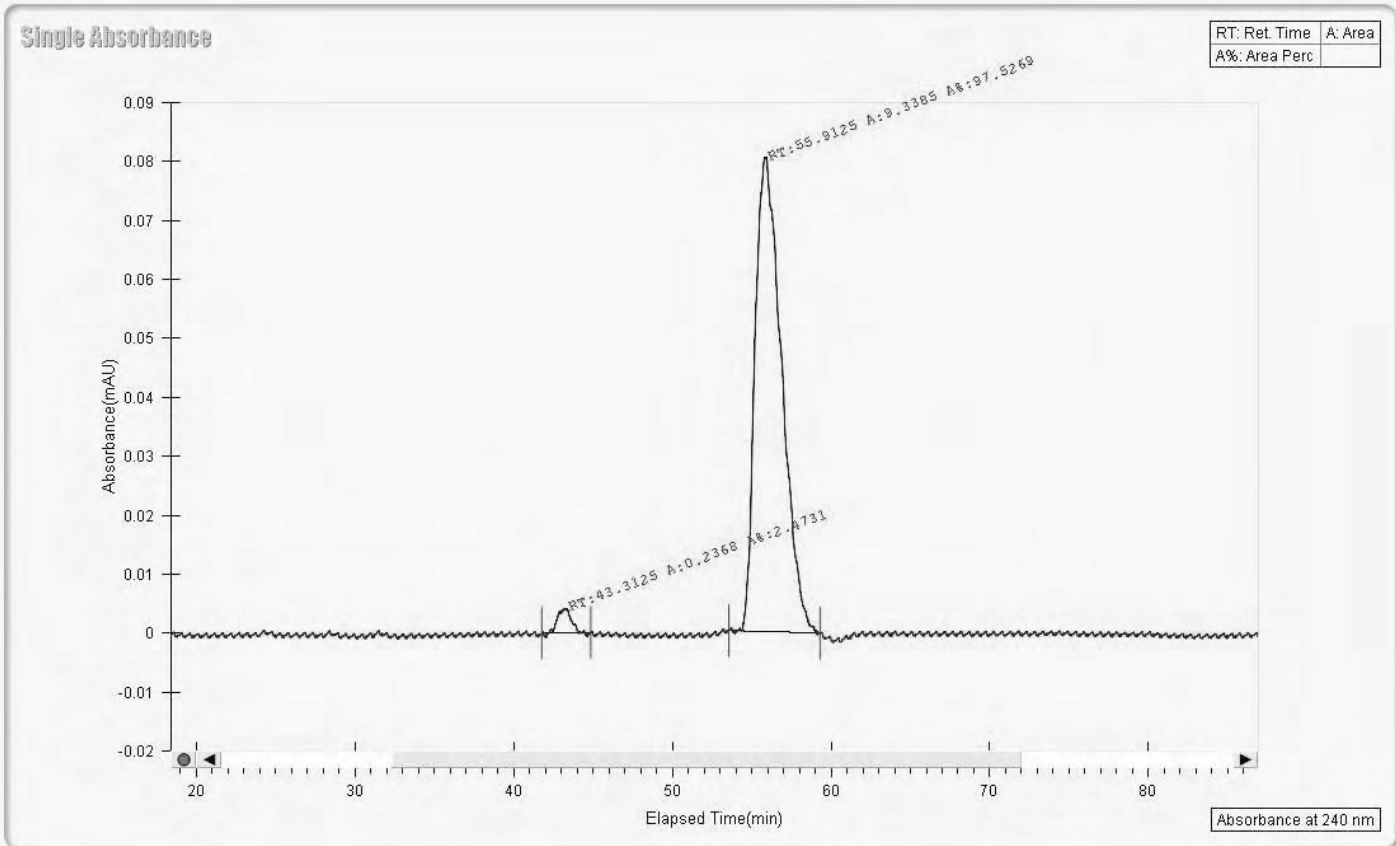

Chiralpak AS-H column $0.46 \mathrm{~cm} \times 25 \mathrm{~cm} 5 \mu \mathrm{m}$

Mobile phase: liq. $\mathrm{CO}_{2} / 2$-propanol/diethylamine, 97:3:0.1

Flow rate $1.0 \mathrm{~mL} / \mathrm{min} \quad \mathrm{UV} 240 \mathrm{~nm}$ 


\section{Enantiomeric Excess Determination of Compound 9}

\section{SFC Trace of Racemic 9}

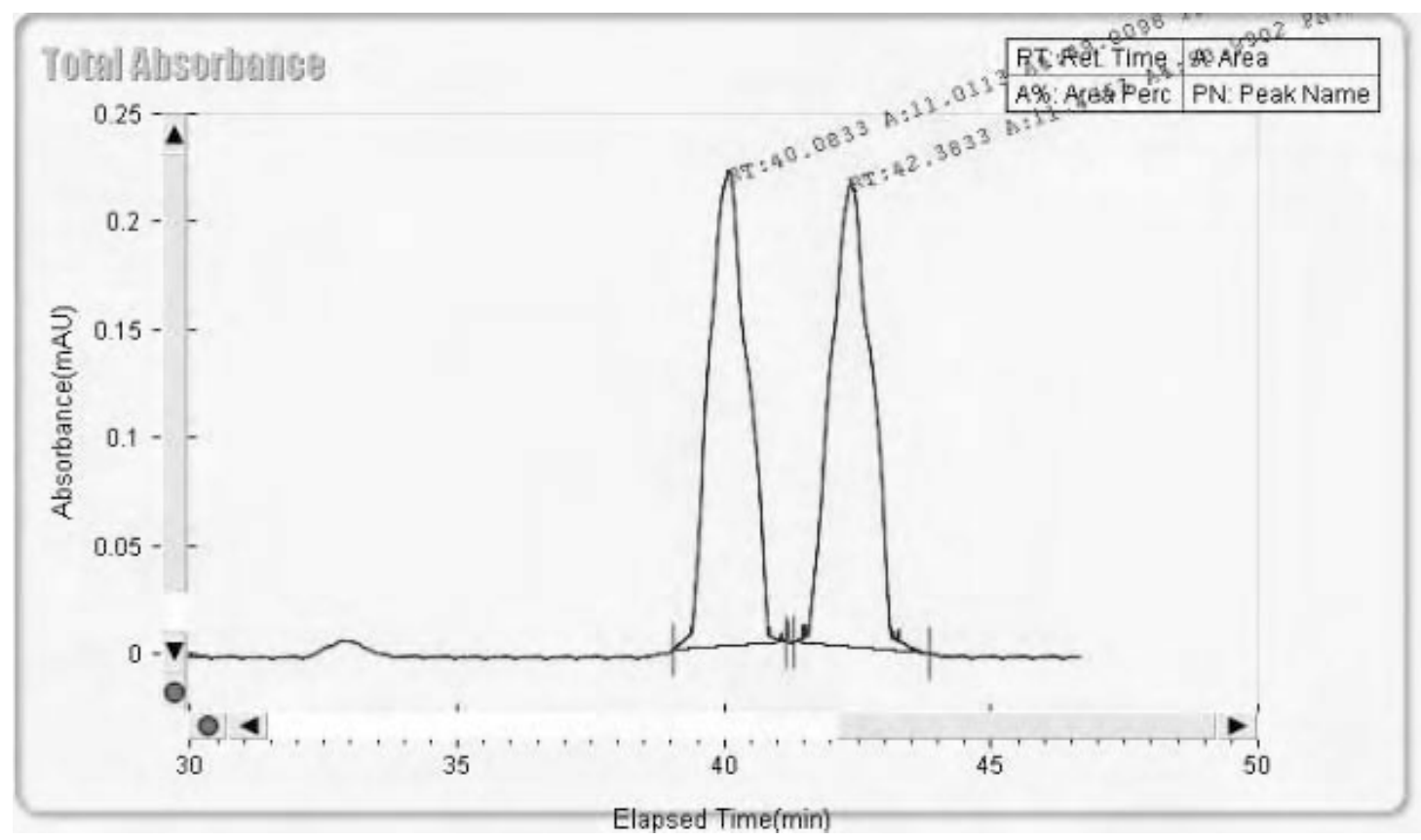

\section{SFC Trace of (S)-3-benzylmorpholine (9)}

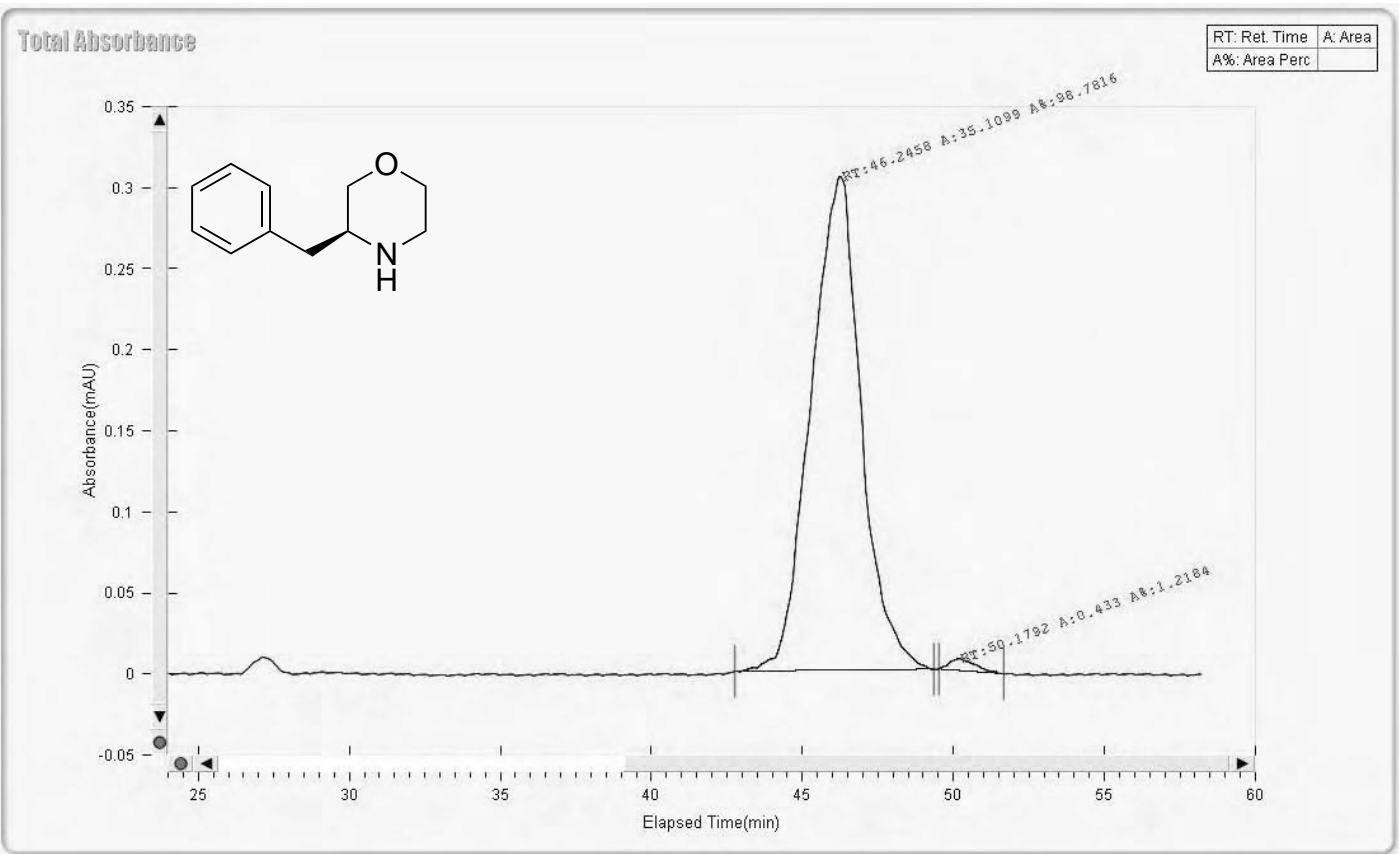

Thar SFC OD-H column $0.46 \mathrm{~cm} \times 25 \mathrm{~cm} 5 \mu \mathrm{m}$

Mobile phase: liq. $\mathrm{CO}_{2} / 2$-propanol/diethylamine, 98:2:0.1

Flow rate $0.9 \mathrm{~mL} / \mathrm{min} \mathrm{UV} 250 \mathrm{~nm}$ 


\section{Enantiomeric Excess Determination of Compound 17}

SFC Trace of Racemic $\mathbf{1 7}$

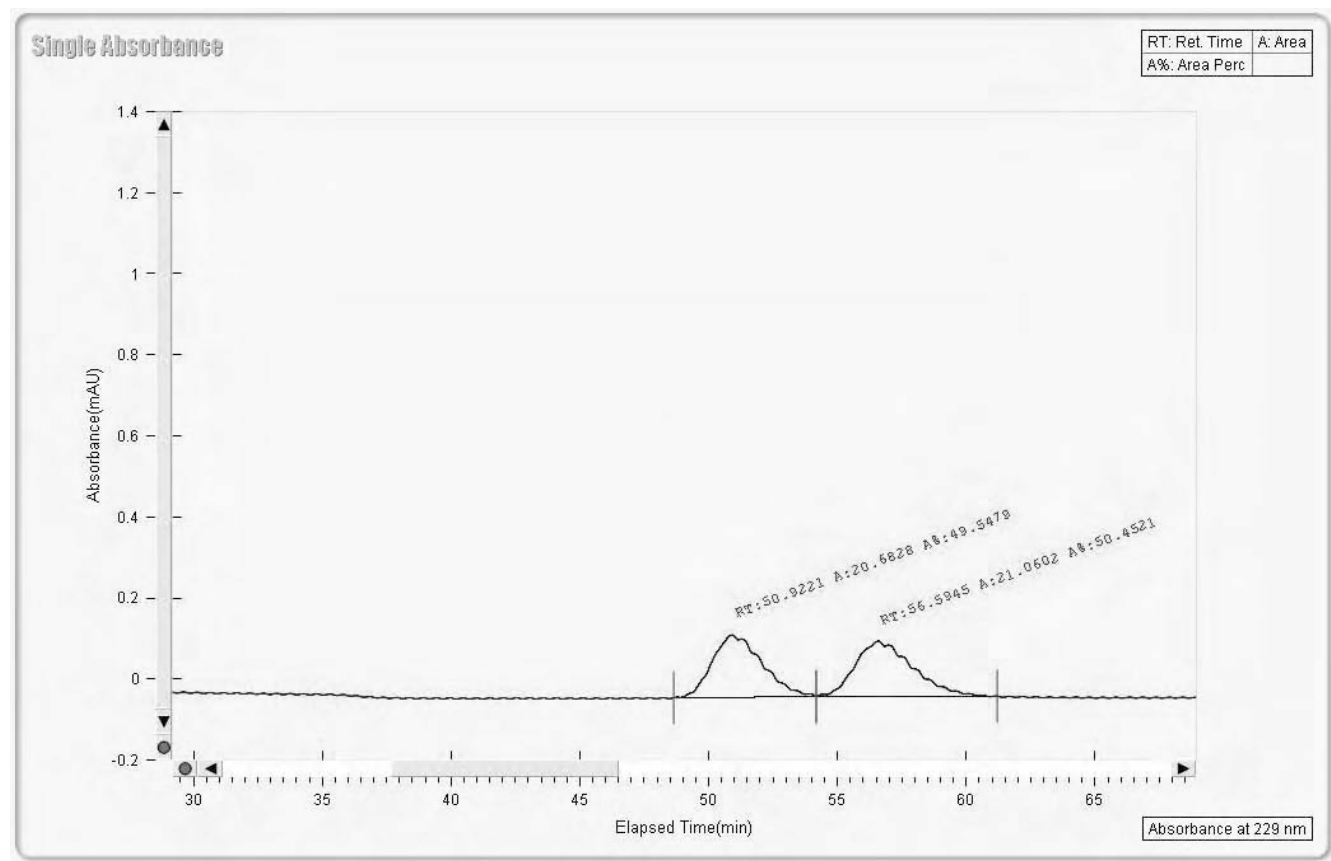

SFC Trace of (R)-3-benzyl-1-(3-phenylprop-2-yn-1-yl)piperazine (17)

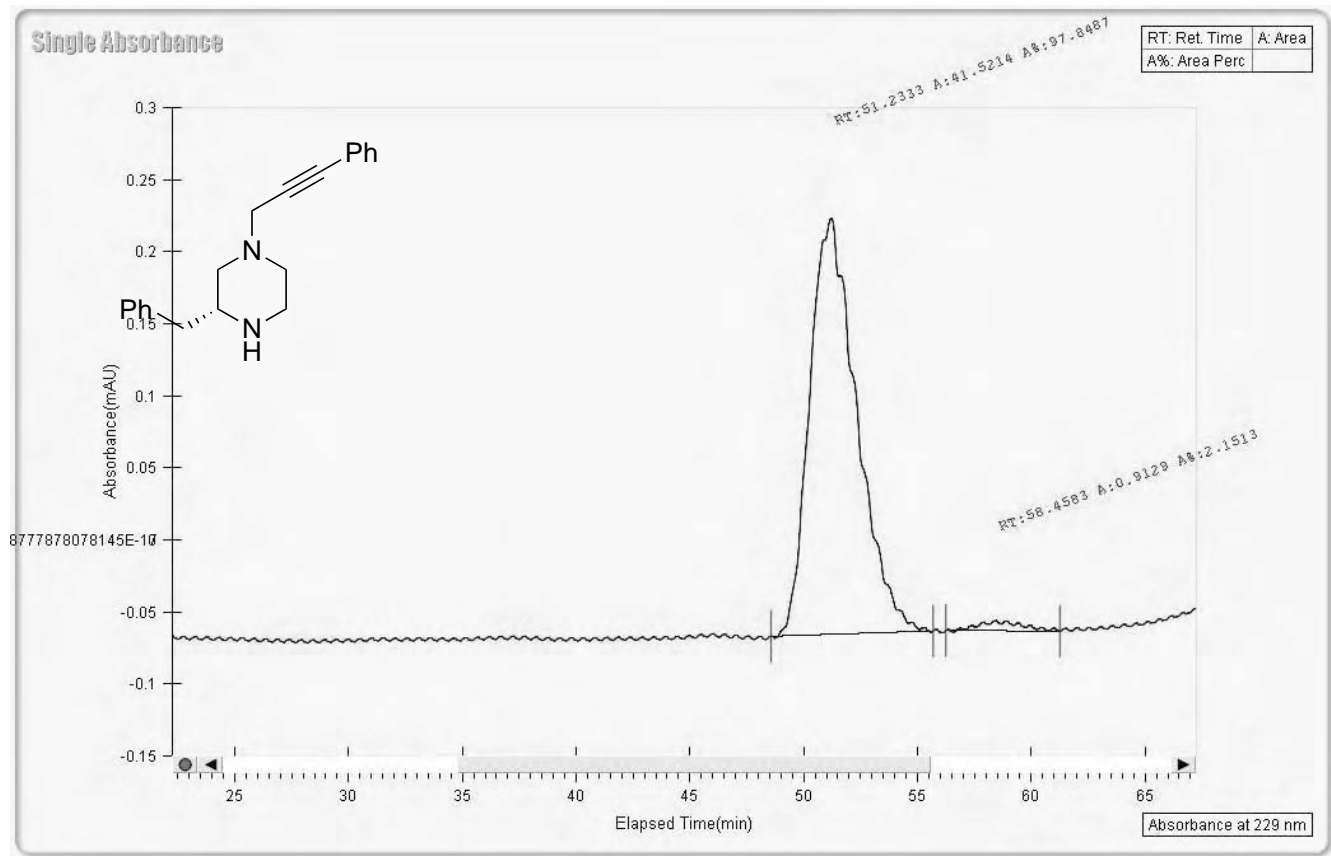


Enantiomeric Excess Determination of Compound 19

HPLC Trace of Racemic 19

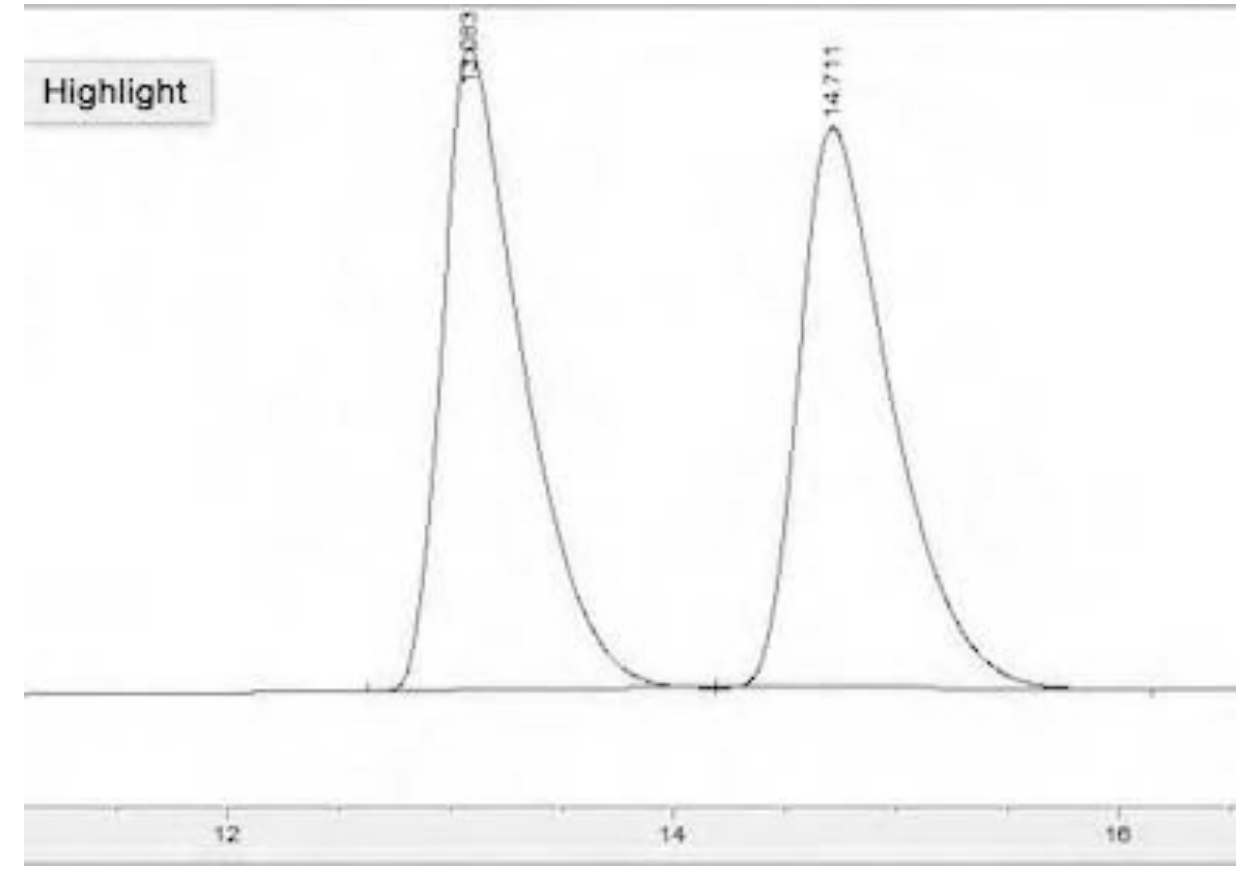

HPLC Trace of (R)-1,3-dibenzylpiperazine (19)

Ph_..

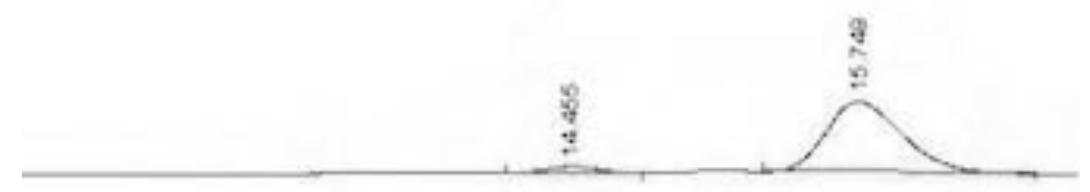

$214 \quad 16$

Chiralcel OJ-RH column, particle size $5 \mu \mathrm{m}, 4.6 \mathrm{~mm} \Phi$ x $150 \mathrm{~mm}$ $37 \%$ Acetonitrile in Water UV $210 \mathrm{~nm}$ 


\section{Enantiomeric Excess Determination of Compound 21}

HPLC Trace of Racemic $\mathbf{2 1}$

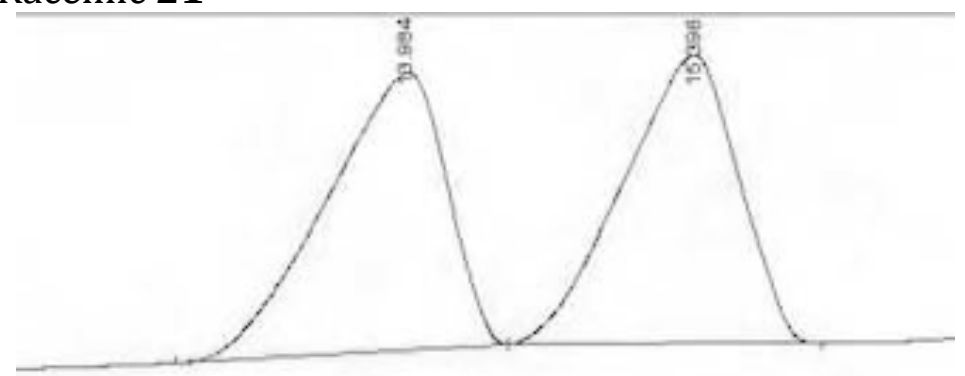

$\begin{array}{lll}14 & 16\end{array}$

HPLC Trace of (R)-1-benzyl-3-ethylpiperazine (21).
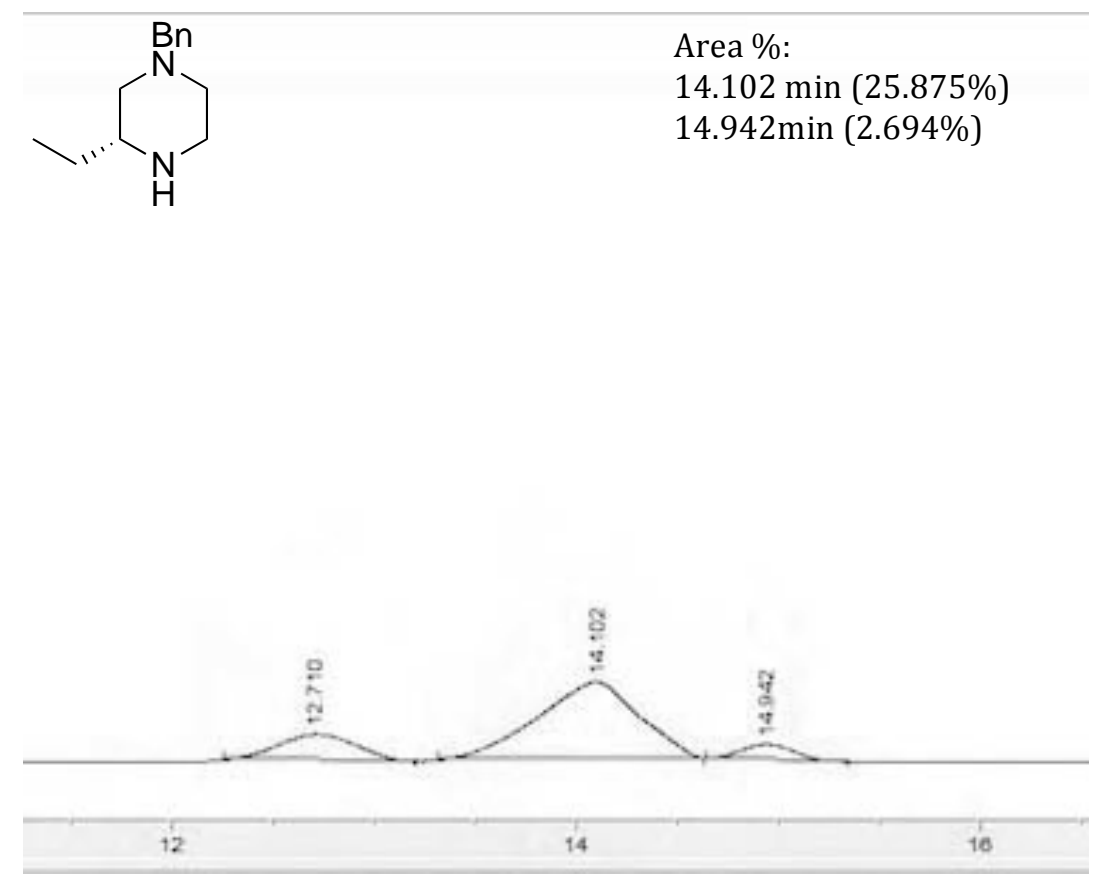

Chiralcel OJ-RH column, particle size $5 \mu \mathrm{m}, 4.6 \mathrm{~mm} \Phi$ x $150 \mathrm{~mm}$ $37 \%$ Acetonitrile in Water UV $230 \mathrm{~nm}$ 